\title{
The identification of QTL controlling ergot sclerotia size in hexaploid wheat implicates a role for the Rht dwarfing alleles
}

Article

Accepted Version

Gordon, A., Basler, R., Bansept-Basler, P., Fanstone, V., Harinarayan, L., Grant, P. K., Birchmore, R., Bayles, R. A., Boyd, L. A. and O'Sullivan, D. M. (2015) The identification of QTL controlling ergot sclerotia size in hexaploid wheat implicates a role for the Rht dwarfing alleles. Theoretical and Applied Genetics, 128 (12). pp. 2447-2460. ISSN 1432-2242 doi: https://doi.org/10.1007/s00122-015-2599-5 Available at https://centaur.reading.ac.uk/42600/

It is advisable to refer to the publisher's version if you intend to cite from the work. See Guidance on citing.

Published version at: http://dx.doi.org/10.1007/s00122-015-2599-5

To link to this article DOI: http://dx.doi.org/10.1007/s00122-015-2599-5

Publisher: Springer

All outputs in CentAUR are protected by Intellectual Property Rights law, including copyright law. Copyright and IPR is retained by the creators or other copyright holders. Terms and conditions for use of this material are defined in the End User Agreement. 


\section{www.reading.ac.uk/centaur}

\section{CentAUR}

Central Archive at the University of Reading

Reading's research outputs online 
The identification of QTL controlling ergot sclerotia size in hexaploid wheat implicates a role for the Rht dwarfing alleles

Anna Gordon ${ }^{1, *}$, Ryan Basler ${ }^{1}$, Pauline Bansept Basler ${ }^{1,2}$, Vicky Fanstone ${ }^{1}$, Lakshmi Harinarayan ${ }^{1,3}$, Paul K Grant $^{4}$, Richard Birchmore ${ }^{1}$, Rosemary A Bayles ${ }^{1,5}$, Lesley A Boyd ${ }^{1}$, Donal M. O’Sullivan ${ }^{1,6}$

1. NIAB, Huntingdon Road, Cambridge, CB3 OLE, UK

2. Syngenta France, Route de Moyencourt, 78910 Orgerus, France

3. Bayer CropScience, Department Technologiepark 38, 9052, Gent, Belgium

4. Department of Plant Sciences, University of Cambridge, Cambridge CB2 3EA, U.K

5. Woodgate Farm, Cascob, Presteigne, Powys, LD8 2NT, UK

6. School of Agriculture, Policy and Development, University of Reading, Reading RG6 6AR, UK

*Corresponding author

Dr Anna Gordon

E-mail: anna.gordon@niab.com

Telephone: 01223342485

Fax: 01223277602

\section{Compliance with Ethical Standards.}

All authors have consented to submit this paper. All authors have followed scientifically good practice as outlined in the Instructions for Authors. This work did not involve human or animal participants.

\section{Conflict of interest}

The authors declare that they have no conflict of interest.

\section{Author's contribution statement}

AG wrote the paper, led much of the experimental work, and analysed genotypic, QTL and phenotypic data. RB (Basler) assisted with field experiments and population handing, and carried out initial QTL analyses of the Year 1 data. AG and RB (Basler) developed the NIAB Ergot Sclerotia Sizing scale. PBB helped with field 
experiments and assisted AG with the generation of the 'Robigus' $\mathrm{x}$ 'Solstice' genetic map. RB (Birchmore) helped with field experiments and seed multiplication. VF and PG helped with field experiments. LH generated additional marker data for the 'Robigus' $\mathrm{x}$ 'Solstice' population. LB co-wrote the manuscript and contributed to statistical analyses. RAB led the HGCA-Defra LINK project LK0963 that undertook the initial screening of UK winter wheat varieties for ergot resistance. DOS conceived and obtained funding for the study - BBSRC and Defra Government Partnership Award (BB/GO20418/1) - led the project team, conducted experiments and cowrote the manuscript.

\section{Acknowledgements}

The work was funded by the Biotechnology and Biological Sciences research Council (BBSRC) and the Department for Environment Food and Rural Affairs (Defra) Government Partnership Award (BB/GO20418/1) to DOS, RAB and AG entitled "Integrated transcriptome and genetic analysis of early events determining tissue susceptibility in the Claviceps purpurea - wheat interaction", and the Home Grown Cereals Authority (HGCA)Defra LINK project LK0963 entitled "Towards a sustainable whole-farm approach to the control of Ergot" to RAB. We acknowledge Dr Chris Burt, then at JIC, for the screening of the 'Robigus' $\mathrm{x}$ 'Solstice' DH population with the chromosome 4DS Kaspar markers, 10920_kasp9 and HV132-1_kasp9. Thanks go to Dr Paul Nicholson for his critical reading of the manuscript, and in conjunction with Dr Chris Burt for useful discussions. The field trials were thanks in part to the NIAB field trials team and we would also like to acknowledge Kate Parsley, Emily Smith, Beth Dickson, and Dan Smith who were additional helpers in inoculating and/or threshing, and scoring of the ergot sclerotia. 


\begin{abstract}
Key message

Four QTL conferring resistance to ergot were identified in the UK winter wheat varieties 'Robigus' and 'Solstice'. Two QTL co-located with semi-dwarfing alleles at the $R h t$ loci $R h t-1 B$ and $R h t-1 D$ implicating a role of these DELLA proteins in infection success of Claviceps purpurea.
\end{abstract}

\begin{abstract}
The fungal pathogen Claviceps purpurea infects ovaries of a broad range of temperate grasses and cereals, including hexaploid wheat, causing a disease commonly known as ergot. Sclerotia produced in place of seed carry a cocktail of harmful alkaloid compounds that result in a range of symptoms in humans and animals, causing ergotism. Following a field assessment of $C$. purpurea infection in winter wheat, two varieties 'Robigus' and 'Solstice' were selected which consistently produced the largest differential effect on ergot sclerotia weights. They were crossed to produce a doubled haploid mapping population, and a marker map, consisting of 714 genetic loci and a total length of $2895 \mathrm{cM}$ was produced. Four ergot reducing QTL were identified using both sclerotia weight and size as phenotypic parameters; QCp.niab.2A and QCp.niab.4B being detected in the wheat variety 'Robigus', and $Q C$ p.niab.6A and $Q C p . n i a b .4 D$ in the variety 'Solstice'. The ergot resistance QTL QCp.niab.4B and $Q C$ p.niab.4D peaks mapped to the same markers as the known reduced height (Rht) loci on chromosomes 4B and 4D, Rht-Bl and Rht-Dl, respectively. In both cases the reduction in sclerotia weight and size were associated with the semi-dwarfing alleles, $R h t-B 1 b$ from 'Robigus' and $R h t-D 1 b$ from 'Solstice'. Two-dimensional, two-QTL scans identified significant additive interactions between QTL QCp.niab.4B and QCp.niab.4D, and between $Q C p . n i a b .2 A$ and $Q C p . n i a b .4 B$ when looking at sclerotia size, but not between $Q C p . n i a b .2 A$ and QCp.niab.4D. The two plant height QTL, QPh.niab.4B and QPh.niab.4D, which mapped to the same locations as QCp.niab.4B and QCp.niab.4D, displayed both epistatic and additive interactions.
\end{abstract}

\title{
Keywords
}

Claviceps purpurea, dwarfing alleles, ergot sclerotia, Rht, Triticun aestivum, wheat 


\section{Introduction}

The ergot fungus Claviceps purpurea infects the ovaries of many species of cereals and grasses, including the economically important cereals wheat, barley, oats, triticale, rye and millet (Tenberge 1999). Conidiospores and ascospores germinate on receptive stigma producing hyphae which grow down the lumen of the stigma towards the ovule tissue, following the route that would normally be taken by pollen tubes (Tudzynski et al. 2004). Within 24 hours of spore germination the fungal germ tube enters the transmitting tissue of the ovule and continues to the ovule base, where the xylem and phloem enter from the rachis. Three to four days post infection, when the hyphae have surrounded the ovary, hyphae become more branched. At 5 days post infection there is complete host cell collapse and the fungus enters the sphacelial stage, where it becomes soft, white and porous, and begins to generate asexual conidiospores. Around 6-7 days post infection an exudate, known as honeydew, is produced consisting of plant sap and C. purpurea asexual, haploid conidia which are believed to be dispersed by rain drops and insects (Tenberge 1999).

The infected ovary is eventually replaced by a purplish-black sclerotium, commonly referred to as an ergot, a hardened mass of white fungal mycelia that is covered with a purplish black outer surface. These overwintering sclerotia eventually give rise to sexual reproductive structures, stroma or apothecia, from which wind-borne ascospores are produced (Mantle and Shaw 1976). Sclerotia contain a wide range of toxic alkaloids produced by the fungus, including ergometrine, ergotamine, ergosine, ergocristine, ergocryptine (which is a mixture of $\alpha$ - and $\beta$ - isomers), ergocornine, and the corresponding -inine epimers. The alkaloids found within sclerotia can cause severe health problems in both humans and animals, responsible for the disease known as ergotism. Ergot alkaloids are classified as tryptophan derived alkaloids with physiological effects occurring from the absorption in the gastrointestinal tract. Toxicity associated with ergot alkaloids occurs through their action on neurotransmitters which can affect the nervous system (De Costa 2002) and at higher doses negatively impact the reproductive system in animals (De Groot et al. 1993).

C. purpurea infection and sclerotia production therefore cause serious quality issues for cereal production. The European Union has imposed limits on the amount of ergot sclerotia allowed in grain destined for human and animal consumption to $0.01 \%$ ( $1 \mathrm{~g}$ per $\mathrm{kg}$ ) (Alexander et al. 2012). As C. purpurea enters the ovary via the stigma and style, incidents of infection are more common in open flowering cereals, with rye and Triticale often being heavily infected. As wheat is a closed-flowering cereal, the window of opportunity for infection is small. 
Consequently only $1-5 \%$ of seed lots examined between 2002 and 2005 by the UK's Official Seeds Testing Station were found to contain ergot sclerotia. However, male sterility, whether genetic or as a consequence of environmental factors such as copper deficiency or drought, results in the flowers gaping open and presents an increased risk of infection. The production of hybrid cereal seed on cytoplasmic male sterile (CMS) mother plants is therefore particularly at risk. Further work completed within populations of CMS lines however, suggests that there are differences in ergot sensitivity which have a genetic basis rather than differences in floral morphology (Miedaner et al 2010).

Complete resistance to $C$. purpurea infection is unknown and a hypersensitive response to this fungus has not been observed in floral tissue (Tenberge 1999). A source of partial resistance was identified in the hexaploid wheat line 'Kenya Farmer' in the 1970s (Platford and Bernier 1970), which resulted in the production of smaller sclerotia (Platford and Bernier 1970, Pageau and Lajeunesse 2006). A reduction in sclerotial size may have an epidemiological impact, resulting in fewer ascospores germinating in the following season (Cooke and Mitchell 1966). Good partial resistance was identified in the tetraploid durum wheat line 9260B-172A, where there was both a reduction in sclerotia size and in the amount of honeydew produced (Menzies 2004). In sorghum nine QTL were identified that affect percentage infection by C. africana (Parh et al. 2008).

As few sources of resistance to $C$. purpurea have been reported in wheat, this study set out to identify UK wheat varieties that differed in their ability to support sclerotia development and then determine the genetic components accounting for these differences. Significant differences were identified between winter wheat varieties in the average weights of sclerotia produced in manually inoculated florets. As the varieties 'Robigus' and 'Solstice' represented the extremes of this variation a doubled haploid population was made from their F1 cross. Phenotypic data was gathered over multiple years of replicated, inoculated field trials to identify the QTL responsible for the differences in sclerotia weight and size seen between 'Robigus' and 'Solstice'. 


\section{Materials and Methods}

\section{Plant materials and Doubled Haploid mapping population}

Fourteen wheat varieties were tested over multiple years (Table 1) as part of the HGCA-Defra LINK project LK0963, "Towards a sustainable whole-farm approach to the control of Ergot" (Bayles et al. 2008). In each year the wheat varieties were sown in replicate field trials at sites near NIAB, Cambridge, UK.

'Robigus', a soft biscuit wheat (KWS UK, Ltd) and 'Solstice', a hard bread wheat (Limagrain UK) were crossed and a doubled haploid (DH) population of 159 lines produced by Saaten Union (Saaten-Union GmbH, Hovedisser Str. 92 D - 33818 Leopoldshoehe, Germany). This DH population was screened for C. purpurea resistance in field trials in 2009/10 and again in 2010/11 at sites near NIAB, Cambridge, UK.

\section{Preparation of Claviceps purpurea isolates}

C. purpurea conidia were obtained by culture on potato dextrose agar (PDA) and on wheat ears of the spring wheat variety 'Paragon'. Ergot sclerotia were surface sterilized for 4 minutes in 5\% sodium hypochlorite and washed four times in sterile distilled water. After surface sterilization the sclerotia were cut in half and placed on 90-mm Petri plates with PDA (Merk 39g/l) with 125mg streptomycin/l. Colonies were sub-cultured on PDA, without antibiotic, after approximately 10 days of culture at $25^{\circ} \mathrm{C}$ in the dark. The resulting C. purpurea colonies were confirmed based on conidial morphology and grown at $20^{\circ} \mathrm{C}$ in the dark for 14 days to harvest conidia. Conidia were scraped from the centre of the colony and suspended in sterile distilled water.

Conidia, collected as honeydew, were produced by inoculating florets of the wheat variety 'Paragon'. 'Paragon' was grown in the glasshouse in Levingtons M2 compost with slow-release osmacote fertilizer, with a $16 \mathrm{~h}$ day length, 6000 Lux and day/night temperatures of $18^{\circ} \mathrm{C} / 10^{\circ} \mathrm{C}$. Ears were inoculated before anthesis with a suspension of conidia from individual isolates (Table 2), using either a hypodermic needle to fill the space between the lemma and palea of each floret (approximately $0.025 \mathrm{ml}$ of suspension at $10^{6}$ conidia/ml), or by dipping wounded ears in the conidia suspension.

Honeydew produced by inoculating 'Paragon' was collected approximately 10 days after inoculation using either a Pasteur pipette or an inoculation loop and suspended in water. Honeydew was collected every 2-3 days 
and the suspensions stored at $5^{\circ} \mathrm{C}$ between collections. Conidial collections were bulked and stored as individual isolates in $10 \%$ glycerol at $-20^{\circ} \mathrm{C}$. Frozen suspensions were found to retain pathogenicity for at least two years.

\section{Claviceps purpurea inoculated field trials}

For the UK winter wheat variety field assessments equal amounts of the five $C$. purpurea isolates (Table 2), at a final concentration of $10^{6}$ conidia $\mathrm{ml}^{-1}$ were used. For the field inoculation of the 'Robigus' $\mathrm{x}$ 'Solstice' $\mathrm{DH}$ population one isolate, 04-97 was selected based on the differential ergot sclerotia size produced on 'Robigus' and 'Solstice' in glasshouse tests and a single spore inoculum was produced and used in all subsequent experiments (called 04-97.1). In 2009/10, due to variable seed set on the primary doubled haploid plants, just $105 \mathrm{DH}$ lines and the parental varieties were sown in $1 \mathrm{~m}$ double-row plots. There were two replicates for all but 17 of the DH lines where seed quantity was limited. The ears from six primary tillers (6 plants) per plot were inoculated with the $C$. purpurea isolate $04-97.1$ between $1^{\text {st }}$ and $7^{\text {th }}$ June 2010 . Twenty florets per ear were handinoculated with a conidia suspension by syringe. In 2010/11 three randomized blocks of all $159 \mathrm{DH}$ lines and the parental varieties were sown in $1 \mathrm{~m}$ plots. Again 20 florets per ear, on the primary tiller of six plants were inoculated per line in each plot. Inoculations were carried out by hand between $18^{\text {th }}$ and $27^{\text {th }}$ May 2011.

Inoculum was prepared daily from newly emerging honeydew exuding from 'Paragon'. The honeydew was diluted with water to a concentration of $6 \times 10^{6}$ conidia/ml. Ears were inoculated when anthers in the middle third of the ear had begun to turn yellow i.e. 1-2 days prior to anthesis. The first fully formed spikelet at the base of each ear was removed to identify the start of the inoculated region. The inoculum was delivered between the lemma and palea of the outer two florets of each spikelet using a $2 \mathrm{ml}$ syringe and needle until the void was full of inoculum. Twenty florets on each ear were inoculated (10 on each side) and the ear labelled with a coloured tag, dated and initialled by the researcher who undertook the inoculation. Ears were harvested 7-8 weeks after anthesis and before the mature ergots began to drop from the ears. Ears were left to dry before removing ergot sclerotia. This inoculation protocol routinely achieved infection in 70-100\% of inoculated spikelets and was designed to minimise the chances for differences in ear morphology or effectiveness of pollen competition to influence the results, as we were more interested in post-infection resistance than 'escape' mechanisms.

\section{Phenotypic assessment of ergot sclerotia development}


Ergot sclerotia were removed by hand from the 20 inoculated florets of each ear and the following parameters measured:

(1) Total sclerotia weight per ear - The weight of all sclerotia collected from one ear.

(2) Average sclerotia weight per ear - The total sclerotia weight per ear/ the total number of sclerotia collected from that ear.

(3) Sclerotia size was determined using a numerical value according to the sclerotia's size within the seed cavity. The NIAB Ergot Scale index points are as follows (Online Resource 1): 0: Dried-out ovule (ovule was infected, but no sclerotia formed); 1: Sclerotia $<2 \mathrm{~mm}$ in length; 2 : Sclerotia $<3 \mathrm{~mm}$ in length; 3: <5 x $2 \mathrm{~mm}$ in size ; 4: Sclerotia > $5 \times 2 \mathrm{~mm}$ in size; 5: > $8 \times 5 \mathrm{~mm}$ in size ; 6: > $10 \times 5 \mathrm{~mm}$ in size; and 7: > 17 x $5 \mathrm{~mm}$ in size.

(4) Average sclerotia size was calculated as follows, where $n_{i}=$ is the number of sclerotia assigned to each NIAB scale from 0 to 7 and $n_{j}$ is the total number of sclerotia.

\section{$\underline{\sum\left(n_{i}\right.} \underline{x}$ NIAB scale $[0$ to 7$\left.]\right)$}

$$
\mathrm{n}_{\mathrm{j}}
$$

\section{Plant height}

Just before harvest plant heights were recorded for each of the DH lines of the 'Robigus' $\mathrm{x}$ 'Solstice' DH population. Plant height was measured as the height from the base of the plant to the bottom of the primary ear. These measurements were taken on ten random plants per line in each plot.

\section{Statistical data analysis}

Analysis of variance (ANOVA) of total sclerotia weight per ear, average sclerotia weight, average sclerotia size and plant heights were undertaken using Restricted Maximum Likelihood (REML). Predicted means for the DH lines were extracted from the REML analyses for each phenotypic data set. Where required, data were transformed using log or square root transformation to achieve near normality and independence of the means and variances. The effects of test replications and genotypes were accounted for in the model. For the 2010 field trial data each inoculated ear was treated as a replicate to derive the predicted means. All analyses were performed using the statistical package Genstat for Windows, release 12 (Payne et al, 2009). Variance 
components for $\mathrm{Vg}$ and $\mathrm{Ve}$ were calculated by REML analysis in Genstat and were used to calculate heritability (Holland et al, 2010) using the following formula:

$\mathrm{h}^{2}=\mathrm{Vg} /(\mathrm{Vg}+\mathrm{Ve})$

$\mathrm{Vg}=$ Estimated genetic variance between lines

$\mathrm{Ve}=\underline{\text { environmental error from DH.reps }}+\underline{\text { residual error }}$

$$
\mathrm{r} \quad(\mathrm{r} * \mathrm{n})
$$

Where $\mathrm{r}$ is number of replicates, $\mathrm{n}$ is number of plants per rep.

\section{Genotyping of the 'Robigus' x 'Solstice' Doubled Haploid population}

Genomic DNA was extracted from leaf tissue using a modified Tanksley method (Fulton et al. 1995), which included an RNase digestion step. Genomic DNA was genotyped by Diversity Arrays Technology Ltd (Akbari et al. 2006) using the DArT array version 2 and by Victoria Agri-Biosciences Centre, Australia for SNPs using the Infinium iSelect 9k chip. In addition, the DH population was screened with two chromosome 4D Kaspar markers, 10920_kasp9 and HV132-1_kasp9 developed for improving marker coverage of the 4D short arm by Dr Chris Burt, and two PCR markers developed for the SNPs causing the Rht-B1b and Rht-D1b allele mutations (Wilhelm 2011).

\section{Construction of a DNA marker linkage map for the 'Robigus' $x$ 'Solstice' DH population}

MapDisto version 1.7.5 Beta 4 (Lorieux 2012) was used to construct a linkage map from 700 DArT, 1902 Infinium iSelect 9k chip SNP markers and the 4 additional Kaspar/PCR markers. Markers that significantly differed from the expected 1:1 segregation ratio were removed from the genotype file before mapping. The Haldane mapping function, with a maximum recombination fraction of 0.3 and LOD of 6 was used to create the map. Several rounds of remapping were undertaken, where co-segregant markers were removed. The "order sequence" function was run using ripple option and bootstrap analysis.

In order to assign linkage groups to physical chromosomes linkage groups were aligned with existing wheat consensus maps. In total $78.4 \%$ of the mapped DArT markers were assigned a chromosomal location (218 out of 278) by reference to the consensus DArT map (Huang et al. 2012) and by searching the DArT BIN maps on the CerealsDB website (Wilkinson et al. 2012). For the Infinium iSelect SNPs markers 72.7\% (314 out of 432) could be assigned a chromosomal location by comparison with the Wang consensus map (Wang et al. 2014).

QTL analyses 
QTL analyses were carried out using the QTL package R/qtl, version 1.33-7 (Broman et al. 2003). Predicted means were obtained for each phenotypic data set from the REML analysis, and used as additional data sets in the QTL analyses. Single marker regression (SMR), interval mapping (IM) and composite interval mapping (CIM) were performed with all ergot phenotypic data sets and plant height. 1000 permutation tests were performed for each phenotypic data set to obtain the 5\% LOD significance thresholds. Peak markers identified by SMR and IM were used as co-factors in CIM analyses. Any significant additional QTL were noted and were examined further using a two-dimensional, two-QTL approach.

\section{Two-dimensional, two-QTL scans}

Two-dimensional genome scans (Broman et al. 2009) were carried out for the $C$. purpurea and plant height traits to identify QTL interactions. Where a pair of loci is identified this analysis is able to diagnose additive and/or epistatic interactions. In addition this analysis confirms the presence of two or more loci, especially if the additional loci have a more modest effect. By comparing the outputs of the scantwo function in R/qtl, one emerges with a pair-wise model which can be illustrated graphically using effect plot and dot plot functions within R. All phenotypic traits analysed by the scantwo function were subjected to 1000 permutation tests, and instead of thresholds, significance p-values are presented. 


\section{Results}

\section{Field assessment of ergot resistance}

Fourteen UK winter wheat varieties were assessed for resistance to $C$. purpurea in inoculated field trials over four growing seasons from 2005 to 2008. Between four and ten varieties were tested every year, some over more than one growing season (Table 1). The total and average sclerotia weight for the wheat varieties 'Xi-19', 'Robigus', 'Solstice', 'Glasgow' and 'Rialto' are shown in Fig. 1.

While there were some differences in ergot sclerotium formation across the different growing seasons (Year, $\mathrm{F}$ prob. $<0.001$ for both phenotypic data sets) the wheat varieties showed consistent, significant differences in total and average sclerotial weights, implying an underlying genetic response. The variety 'Robigus' produced significantly lower total and average sclerotia weights to 'Solstice' $(\mathrm{P}<0.001)$ ', 'Rialto' $(\mathrm{P}<0.001)$ and 'Xi19' $(\mathrm{P}=0.001$ ), but not 'Glasgow' (total weight, $\mathrm{P}=0.263$ and average weight, $\mathrm{P}=0.347$ ). As the biggest difference in ergot sclerotia sizes was between 'Robigus' and 'Solstice', these varieties were selected for genetic mapping to locate loci influencing ergot sclerotial development in hexaploid wheat.

Frequency distributions across the 'Robigus' $x$ 'Solstice' DH population indicated a normal, quantitative distribution for average sclerotia size (Fig. 2), while the frequency distributions of total and average sclerotia weight were positively skewed, (Fig. 2). Plant height was bi-modally distributed and confirms the postulated presence of different $R h t$ dwarfing alleles in 'Robigus' and 'Solstice', 'Robigus' carrying the $R h t$ - $B 1 b$ allele at locus $R h t-B 1$ on chromosome 4B, while 'Solstice' carries the Rht-Dlb allele on chromosome 4D (Figure 5).

Analysis of variance indicated significant differences (F prob. $<0.001)$ between the parents and the DH lines for all ergot sclerotial phenotypes . Transgressive segregation was apparent for all sclerotial phenotypes, with five DH lines having significantly $(\mathrm{t}$-test $<0.001)$ lower sclerotial weights than 'Robigus' and 13 lines showing smaller sclerotia at a t-test probability of $<0.001$. Heritability values indicated that all three sclerotia phenotypes and plant height had a relatively high genetic component contributing to the phenotypes. The highest $h^{2}$ values were obtained for average sclerotia weight $\left(h^{2}=0.7616\right)$ and average sclerotia size $\left(h^{2}=0.7242\right)$, with total sclerotia weight having a slightly lower $h^{2}$ value of 0.6212 (all values shown calculated using 2011 field data). Plant height had an $h^{2}$ value of 0.9138 . The full set of $h^{2}$ values can be found in Online Resource 2. 


\section{Identification of QTL underlying the response to ergot infection in the 'Robigus' $x$ 'Solstice' cross}

A genetic marker map, total length $2895 \mathrm{cM}$, consisting of 38 linkage groups and representing all 21 chromosomes of hexaploid wheat was constructed for the 'Robigus' $\mathrm{x}$ 'Solstice' cross. The map consisted of 714 loci; 432 Infinium iSelect SNPs and 278 DArTs markers, plus two PCR markers which distinguished the $R h t$ mutant alleles from the wild type; Rht-Dla/b and Rht-Bla/b (Willhelm 2011), and two additional SNP markers tightly linked to the Rht locus on 4DS. Details of all markers and their positions can be found in Online Resources 3 and 4.

The QTL reported are those identified using the predicted means and having a LOD value above the global threshold given in Table 3. Three QTL, QCp.niab.2A, QCp.niab.4B and QCp.niab.4D were consistently identified in 'Robigus' on chromosomes 2A, 4B and 4D, respectively using the phenotypic data sets for average sclerotia size and average sclerotia weight (Fig. 3). The QTL regions on 4B and 4D were also detected using total sclerotia weight per ear. In general, the percentage phenotypic variance explained by individual QTL was relatively small, ranging from a maximum of $4.76 \%$ for $Q C p . n i a b .2 A, 5.88 \%$ for $Q C p . n i a b .4 B$ and $13.94 \%$ for QCp.niab.4D. While some QTL were not significant using IM in either 2010 or 2011, all three QTL were significant in both years using CIM (Table 3). A smaller effect QTL, QCp.niab.6A, was detected with the 2010 total sclerotia weight per ear data set in 'Solstice' on chromosome 6A. QCp.niab.6A had a LOD of 3.49 and a percentage variance of $3.14 \%$.

As 'Robigus' and 'Solstice' were known to carry different semi-dwarfing alleles, 'Robigus' having Rht-B1b (located on chromosome 4B) and 'Solstice' having Rht-Dlb (located on chromosome 4D), plant height was mapped in the 'Robigus' x 'Solstice' DH population. CIM identified two QTL for plant height, QPh.niab.4B and QPh.niab.4D on chromosomes 4B and 4D, respectively, where the PCR markers Rht-B1b and Rht-D1b were the peak markers. In 2010 QPh.niab.4B and QPh.niab.4D accounted for $6.95 \%$ and $13.79 \%$ of the phenotypic variance in plant height, while in 2011 they accounted for $24.01 \%$ and $31.70 \%$, respectively. Interestingly, a QTL for plant height was also identified with the 2010 plant height data set in the same region as QCp.niab.6A, with the height-reducing allele and the resistance allele both coming from 'Solstice' (Online Resource 5). 
Two-dimensional, two-QTL scans were undertaken to identify pair-wise interactions between QTLs (Online Resource 6). These analyses identify additive effects $\left(\mathrm{LOD}_{\mathrm{av1}}\right)$ between QTL, where the presence of two genes (usually from different pathways) has a straightforward additive effect on the phenotype. They also identify epistatic-interacting effects $\left(\mathrm{LOD}_{\mathrm{i}}\right)$ where the effect of one QTL can only be shown in the presence of another, usually explained by their sequential action in the same pathway. These analyses were undertaken using the average sclerotia size and plant height data sets. Additive effects were seen with the QTL for average sclerotia size, the largest effect being seen with the 2010 data set between QTL QCp.niab.4B and QCp.niab.4D (LOD ${ }_{\mathrm{av} 1}$ $=6.81 ; \mathrm{P}<0.001)$. With the 2011 average sclerotia size data set, the same QTL interaction had a $\mathrm{LOD}_{\mathrm{av1}}=3.01$; however this was just over the significance threshold with a p-value of 0.172 . An additive interaction was also seen between QCp.niab.2A and QCp.niab.4B, with both the $2010\left(\mathrm{LOD}_{\mathrm{av} 1}=3.03 ; \mathrm{P}=0.072\right)$ and $2011\left(\mathrm{LOD}_{\mathrm{av} 1}\right.$ $=3.93 ; \mathrm{P}=0.037)$ data sets, however no interaction was identified between $Q C$ p.niab. $2 A$ and $Q C p . n i a b .4 D$. To visualise the QTL additive effects for average sclerotia size dot plots of the phenotypic averages of the lines carrying the QTL QCp.niab.2A, QCp.niab.4B and QCp.niab.4D alone or in combination are presented (Fig. 4).

Two-dimensional, two-QTL scans suggested that the relationship between the plant height QTL QPh.niab.4B and QPh.niab.4D is both epistatic $\left(2010, \mathrm{LOD}_{\mathrm{i}}=16.01 ; \mathrm{P}<0.001\right.$ and $\left.2011, \mathrm{LOD}_{\mathrm{i}}=7.84 ; \mathrm{P}<0.001\right)$ and additive $\left(2010, \mathrm{LOD}_{\mathrm{av} 1}=23.97 ; \mathrm{P}<0.001\right.$ and 2011, $\left.\mathrm{LOD}_{\mathrm{av} 1}=11.79 ; \mathrm{P}<0.001\right)($ Online Resource 6). An additional height QTL to QPh.niab.4B and QPh.niab.4D was identified using two-dimensional two-QTL analysis on chromosome 2B, designated $Q P h . n i a b .2 B$, which has an epistatic interaction with $Q P h . n i a b .4 B$ $\left(\mathrm{LOD}_{\mathrm{i}}=7.37 ; \mathrm{P}<0.001\right)$, further reducing the height of Rht-Blb carrying plants (Online Resource 5). The dependence of expression of a phenotype for $Q P h . n i a b .2 B$ on the presence of $Q P h . n i a b .4 B$ may indicate why QPh.niab.2B was not detected by IM alone. 


\section{Discussion}

Ergot is a plant disease of considerable importance to human and animal health due to the toxic effects of alkaloids present in the sclerotia (De Costa 2002). Few sources of genetic resistance to C. purpurea have been reported, with the best source of resistance identified to date being found in a durum wheat genotype (Menzies 2004). In this study we report genetic variation in the response of hexaploid wheat varieties to C. purpurea and identify interacting QTL in the varieties 'Robigus' and 'Solstice' that influence the size and weight of sclerotia produced by $C$. purpurea.

Together the three QTL QCp.niab.2A, QCp.niab.4B and QCp.niab.4D at best only explained $24.6 \%$ of the phenotypic variation for sclerotial weight (2010 data set), while dividing the percentage phenotypic variance by its corresponding heritability value $\left(h^{2}=0.78\right)$ gave a maximum genetic variation of $31.7 \%$. This implies that the majority of the genetic variation affecting ergot development and sclerotium formation in the 'Robigus' $\mathrm{x}$ 'Solstice' population was not detectable. This is likely due to the presence of many small genetic influences affecting sclerotial development, each genetic locus producing a phenotypic effect below the current resolution of QTL analysis, which is limited by the modest size of the population.

The QTL with the largest effect, QCp.niab.4B and QCp.niab.4D, mapped to the same location as the Reduced Height (Rht) loci Rht-Bl and Rht-Dl (Peng et al. 1999), with the resistance effect co-segregating with the dwarfing alleles $R h t-B 1 b$ (from 'Robigus') and $R h t-D 1 b$ (from 'Solstice'), respectively. As a result, the general trend was for shorter DH lines to produce smaller sclerotia, although there was significant overlap in the sclerotial size distributions of tall, semi-dwarf and double-dwarf plant size classes indicating the presence of additional genes, not linked to height, influencing sclerotia size (Fig. 5).

Rht-Bl and Rht-Dl encode for DELLA proteins (Peng et al. 1999). In Arabidopsis DELLA proteins have been shown to be nuclear-located and are putative transcriptional regulators that interact with the gibberellic acid receptor protein GID1 (GA-Insensitive Dwarf), resulting in growth repression. In the presence of gibberellic acid (GA) the DELLA proteins are degraded via the $26 \mathrm{~S}$ proteasome SCF complex, resulting in subsequent stimulation of plant growth (Dill et al. 2004). The gain-of-function dwarfing alleles $R h t-B 1 b$ and $R h t-D 1 b$ produce GA-insensitive mutant DELLA proteins, resulting in a partially stable pool of DELLA protein that continues to suppress plant growth, producing semi-dwarfed plants (Pearce et al. 2011). 
The association between $Q C p . n i a b .4 B$ and $R h t-B 1 b$, and $Q C p . n i a b .4 D$ and $R h t-D 1 b$ may be pleiotropic, i.e. the same locus affects both sclerotium formation and plant height, or could be due to close genetic linkage of functionally independent genes. In the latter case, height and ergot resistance should be genetically separable if a sufficiently high resolution mapping approach was brought to bear. If the former is the case, attention should be devoted to testable hypotheses that might flow from a postulated pleiotropy between wheat DELLA function and ergot sclerotia size. Although neither scenario can be ruled out, some further observations lend more weight to the pleiotropy scenario.

Firstly, wheat DELLA/Rht genes have been demonstrated to have potential pleiotropic effects on disease resistance to multiple pathogens, with gain-of-function mutant alleles conferring increased susceptibility to biotrophic pathogens and increased resistance to necrotrophic pathogens (Saville et al. 2011). In Arabidopsis, DELLA mutants have been shown to suppress hypersensitive cell death, leading to increased resistance to necrotrophic pathogens and increased susceptibility towards pathogens with a biotrophic life stage (Navarro et al. 2008). In the wheat-Fusarium Head Blight (FHB) pathosystem, the semi-dwarfing alleles $R h t-B 1 b$ and $R h t$ $D 1 b$ were associated with decreased resistance to primary infection (Type I resistance) of wheat florets by Fusarium species, with the early stages of Fusarium infection currently thought to represent a biotrophic phase (Hilton et al. 1999; Draeger et al. 2007, Srinivasachary et al. 2009). However, while C. purpurea is considered a biotroph, in the present study the $R h t$ gain-of-function mutant alleles were associated with increased resistance and not susceptibility. The Rht alleles therefore have contrasting effects on the infection of florets and ovules by C. purpurea and Fusarium species.

Secondly, the association between ergot resistance and GA-regulated plant height may not be confined to the Rht-D1 and Rht-B1 loci, as the small effect QTL QCp.niab.6A was detected with both the plant height and total sclerotia weight per ear phenotypic data sets, with the 'Solstice' allele being responsible for both reduced sclerotia and reduced height. Previous studies have identified plant height genes on chromosome 6A (Watanabe 2008), the alleles Rht14, Rht16 and Rht18 at this locus conferring GA-sensitive reduced plant height. Unfortunately, we were not able to confirm a common location for QCp.niab.6A and the plant height QTL reported on chromosome 6A (Watanabe 2008). 
Thirdly, there seems to be a more general association between hormone signalling and quantitative development of ear diseases in wheat. A QTL for Type I FHB resistance has also been reported on chromosome 2A, however common markers were not available to compare the position of this QTL with the ergot resistance QTL QCp.niab.2A found in this study (Lin et al. 2006, Diethelm et al. 2014). Characterisation of the peak marker for the 2A FHB QTL suggests that the gene underlying the QTL may be a wheat homologue of NPR1 (nonexpresser of pathogenesis related protein 1) (Diethelm et al. 2014). NPR1 is at the heart of hormonal cross-talk between the salicylic acid (SA) and jasmonic acid (JA) pathways, being involved in the SA-mediated suppression of the JA pathway (Spoel et al. 2003). The functional annotation of transcripts differentially expressed between ovaries inoculated with $C$. purpurea versus mock-inoculated ovaries in RNA-Seq experiments also highlights hormone signalling as one of the most responsive functional categories (unpublished data).

Gibberellins play a crucial role in many aspects of plant development. Active forms of these phytohormones are known to control processes such as seed germination, stem elongation, floral development and anther extrusion (Cheng et al. 2004, Peng et al. 1997). C. purpurea may have evolved an ability to manipulate the endogenous host hormone signalling pathways to command the resources necessary to produce sclerotia many times the fresh weight of a fully developed grain. Mutations in key hormone signalling pathway genes, such as the Rht$B 1 b$ and $R h t-D 1 b$ alleles, are therefore attractive candidates that could explain how the ability to re-programme host resource allocation is partly compromised in the absence of any symptoms resembling a typical immune response. In the case of the Rht mutants one may speculate that perturbed GA levels may interact with normal mechanisms by which $C$. purpurea colonise floral tissues, resulting in altered levels of colonisation. In semidwarf and dwarf lines GA levels increase in expanding leaf tissues (Appleford and Lenton 1991, Wu et al. 2011), but to our knowledge GA levels in ovule tissue pre-pollination have never been measured and are a potential avenue of further investigation.

An alternative hypothesis is that $C$. purpurea produces and exudes its own GA which acts as a pathogenicity factor (for example by triggering an increase in the nutrient flow into the ovule tissue resulting in larger sclerotia). In this regards, it is noteworthy perhaps that the reference Claviceps purpurea genome (reference Helmholtz genome dB and Schardl et al, 2013)possesses a duplicated GA synthesis gene cluster with similarity to that found in the GA-synthesizing pathogen Fusarium fujikori (Tudzynski \& Hölter, 1998, Tudzynski 2005). We have shown that these genes are highly expressed in the first 7 days of infection (A. Gordon, manuscript in 
preparation). So in the case of the $R h t$ mutants one may speculate that host GA insensitivity has the serendipitous consequence of reducing response to an exogenous pathogen-derived GA signal required to develop full potential sclerotial size. 


\section{Figure Legends}

Fig. 1 Inoculated field trial data showing the mean across replicates for total sclerotia weight per ear and average sclerotia weight for five UK winter wheat varieties. Data was collected from replicated field trials over 4 years, from 2005 to 2008. Error bars show the standard error between replicates, apart from 2006, where all replicates of sclerotia were pooled together before weighing

Fig. 2 Distribution of total sclerotia weight per ear, average sclerotia size, average sclerotia weight and plant height phenotypes in the 'Robigus' $x$ 'Solstice' double haploid population. Arrowheads indicate the phenotypic averages of the parents

Fig. 3 QTL positions for ergot sclerotia total and average weights, sclerotia size and plant height in the 'Robigus' x 'Solstice' cross following CIM or IM analysis. QTL positions are shown to the right of the linkage maps on chromosomes 2A, 4B, 4D and 6A. QTL bars represent 1.5 LOD support intervals around the peak score marker. Marker locations are shown to the left of each linkage map, along with marker number, chromosome identifier and position in centimorgans from the top of the linkage group. The full marker names can be found in Table S1

Fig. 4 Phenotypic distribution for sclerotia size in 'Robigus' $x$ 'Solstice' doubled haploid lines carrying one or more of the three major QTL contributing to reduced sclerotia size, QCp.niab.2A, QCp.niab.4B and QCp.niab.4D. The peak marker used to identify each QTL, the QTL parental origin and chromosomal location are indicated above each plot. Phenotypic data from 2010 and 2011 field trials is shown. Error bars are \pm 1 standard errors

Fig. 5 Relationship between ergot sclerotia size and plant height in doubled haploid lines from the cross 'Robigus' x 'Solstice', 2011 data set. The Rht-Bl and Rht-Dl $a$ (wild-type) and $b$ (dwarf mutant) alleles carried by each line are indicated. 'Robigus' genotype $R h t-B 1 b / R h t-D l a$ and 'Solstice' genotype $R h t-1 B a / R h t-1 D b$ 
Table 1 UK winter wheat varieties screened for ergot resistance in inoculated field trials

Table 2 Claviceps purpurea isolates

Table 3 QTL identified in the 'Robigus' $\mathrm{x}$ 'Solstice' cross for ergot sclerotia development and plant height

\section{Electronic Supplementary Material / Online Resources}

Online Resource 1 The NIAB ergot sclerotia sizing scale

Online Resource 2 Heritability of all traits recorded from the Robigus x Solstice population over two years of field trials. $h^{2}=\mathrm{Vg} /(\mathrm{Vg}+\mathrm{Ve})$. Variance components were estimated by REML as implemented within GenStat (Payne et al 2009)

Online Resource 3 'Robigus' x 'Solstice' genetic map, including co-segregating markers.

Online Resource 4 Complete linkage map of the 'Robigus' x 'Solstice' doubled haploid population, consisting of 38 linkage groups, representing all 21 chromosomes of hexaploid wheat and having a total length of $2895 \mathrm{cM}$. Marker locations are shown to the right of each linkage group along with marker number, chromosome identifier and position in centimorgans from the top

Online Resource 5 (a) Dot plots showing the effect of $Q C p . n i a b .6 A$ on total sclerotia weight and QPh.niab.6A on plant height in 2010. Doubled haploid lines with the 'Solstice' allele at the QTL positions on chromosome 6A have lower total sclerotia weights and are shorter. (b) Effect plot and dot plot for QPh.niab.4B and its interacting partner $Q P$ h.niab. $2 B$ showing epistatic effects on plant height. $Q P h . n i a b .2 B$ only reduces height in the presence of QPh.niab.4B

Online Resource 6 Summary of outputs from two-dimensional, two-QTL scans 
Table 1 Winter wheat varieties screened for ergot resistance in inoculated field trials

\begin{tabular}{|l|l|l|}
\hline $\begin{array}{l}\text { Year of } \\
\text { field trial }\end{array}$ & $\begin{array}{c}\text { Number of ears per variety } \\
\text { inoculated with Claviceps purpurea }\end{array}$ & \multicolumn{1}{c|}{ Wheat varieties screened } \\
\hline $2004 / 05$ & $\begin{array}{l}10 \text { ears (2 reps) } \\
\text { Variable number of florets inoculated } \\
\text { per ear }\end{array}$ & $\begin{array}{l}\text { Caphorn, Drifter, Paragon, Rialto, Robigus, } \\
\text { Solstice, Tommi, Welford, Xi19 }\end{array}$ \\
\hline $2005 / 06$ & $\begin{array}{l}3 \text { ears (4 reps) } \\
20 \text { florets inoculated per ear }\end{array}$ & $\begin{array}{l}\text { Apache, Caphorn, Drifter, Paragon, Rialto, } \\
\text { Robigus, Solstice, Tommi, Welford, Xi19 }\end{array}$ \\
\hline $2006 / 07$ & $\begin{array}{l}12 \text { ears (2 reps) } \\
10 \text { florets inoculated per ear }\end{array}$ & $\begin{array}{l}\text { Brompton, Cordiale, Glasgow, Mascot, } \\
\text { Rialto, Robigus, Solstice, Xi19 }\end{array}$ \\
\hline $2007 / 08$ & $\begin{array}{l}10 \text { ears (1 rep) } \\
20 \text { florets inoculated per ear }\end{array}$ & \begin{tabular}{l} 
Glasgow, Robigus, Solstice, Xi19 \\
\hline
\end{tabular}
\end{tabular}


Table 2 Claviceps purpurea isolates used in inoculated field trials (Bayles et al, 2008)

\begin{tabular}{|l|l|l|l|}
\hline $\begin{array}{l}\text { Isolate } \\
\text { name }\end{array}$ & $\begin{array}{l}\text { Year of } \\
\text { collection }\end{array}$ & Location & Plant host \\
\hline $04-02$ & 2004 & Cambridge & Blackgrass (Alopecurus myosuroides) \\
\hline $04-29$ & 2004 & Little Saxham, Suffolk & Wheat (cv. Hereward) \\
\hline $04-97$ & 2004 & Long Hoos IV, Rothamsted & Blackgrass (Alopecurus myosuroides) \\
\hline $03-20$ & 2003 & Elm Farm, Cirencester & Wheat (cv. Chablis) \\
\hline $03-43$ & 2003 & Elm Farm, Wakelyn's, Suffolk & Wheat (cv. Claire) \\
\hline
\end{tabular}


Table 3 QTL identified in the 'Robigus' x 'Solstice' cross for ergot sclerotia development and plant height

\begin{tabular}{|c|c|c|c|c|c|c|c|c|}
\hline $\begin{array}{l}\text { QTL } \\
\text { designation }\end{array}$ & $\begin{array}{c}\text { Chromosome } \\
\text { location }\end{array}$ & Peak Marker & $\begin{array}{l}\text { Position } \\
\text { (cM) }\end{array}$ & $\begin{array}{l}\text { LOD } \\
\text { value }\end{array}$ & $\begin{array}{l}\text { \%Variance } \\
\text { explained }\end{array}$ & $\begin{array}{l}{ }^{\mathrm{a}} \text { Parental } \\
\text { Allele }\end{array}$ & $\begin{array}{l}{ }^{\mathrm{b}} \text { Phenotypic } \\
\text { data set }\end{array}$ & ${ }^{\mathrm{c}}$ QTL Analysis \\
\hline \multirow[t]{3}{*}{ QCp.niab.2A } & \multirow[t]{3}{*}{$2 \mathrm{~A}$} & wsnp_BQ168780B_Ta_2_1 & 108 & 4.631 & 4.17 & \multirow[t]{3}{*}{$\mathrm{R}$} & 2010-SS & SMR,IM,CIM \\
\hline & & wsnp_Ex_c2337_4379619 & 134 & 3.899 & 2.47 & & 2011-SS & SMR,IM, CIM \\
\hline & & wsnp_BQ168780B_Ta_2_1 & 108 & 5.28 & 4.76 & & 2010-SW & SMR,IM, CIM \\
\hline \multirow[t]{4}{*}{ QCp.niab.4B } & \multirow[t]{6}{*}{$4 \mathrm{~B}$} & Rht-B1b & 72.76 & 4.827 & 4.35 & \multirow[t]{6}{*}{$\mathrm{R}$} & 2010-SS & CIM \\
\hline & & wsnp_CAP12_c13_8078 & 70.9 & 6.497 & 4.11 & & 2011-SS & SMR,IM, CIM \\
\hline & & Rht-B1b & 72.0 & 6.527 & 5.88 & & 2010-SW & CIM \\
\hline & & wsnp_CAP12_c13_8078 & 70.9 & 8.52 & 5.39 & & 2011-SW & SMR,IM, CIM \\
\hline \multirow[t]{2}{*}{ QPh.niab.4B } & & Rht-B1b & 72.75 & 11.67 & 6.95 & & 2010-PH & CIM \\
\hline & & Rht-B1b & 72.75 & 24.25 & 24.0 & & 2011-PH & SMR,IM, CIM \\
\hline \multirow[t]{4}{*}{ QCp.niab.4D } & \multirow[t]{6}{*}{$4 \mathrm{D}$} & Rht-D1b & 13 & 13.53 & 12.19 & \multirow[t]{6}{*}{$S$} & 2010-SS & SMR,IM, CIM \\
\hline & & Rht-D1b & 8 & 3.45 & 2.19 & & 2011-SS & CIM \\
\hline & & Rht-D1b & 14 & 15.4 & 13.94 & & 2010-SW & SMR,IM, CIM \\
\hline & & Rht-D1b & 12 & 12.07 & 10.87 & & 2010-TW & SMR,IM, CIM \\
\hline \multirow[t]{2}{*}{ QPh.niab.4D } & & Rht-D1b & 9 & 23.16 & 13.79 & & 2010-PH & SMR,IM, CIM \\
\hline & & Rht-D1b & 9 & 32.01 & 31.70 & & 2011-PH & CIM \\
\hline QPh.niab.6A & $6 \mathrm{~A}$ & wPt-665636_NA & 0 & 4.76 & 2.83 & $S$ & 2010-PH & SMR, IM \\
\hline
\end{tabular}

${ }^{a}$ The contributing parental alleles, $\mathrm{R}=$ 'Robigus' and $\mathrm{S}=$ 'Solstice' confer smaller sclerotia and shorter plants. ${ }^{\mathrm{b}} \mathrm{Phenotypic}$ data codes: SS - Average Sclerotia Size; SW Average Sclerotia Weight; TW - Total Sclerotial Weight per Ear; and PH - Plant Height. ${ }^{\mathrm{c}} \mathrm{QTL}$ analyses were performed using single marker regression (SMR), Interval Mapping (IM) and Composite Interval Mapping (CIM). The position of the QTL is shown in centimorgans (cM). 


\section{References}

Akbari M, Wenzl P, Caig V, Carling J, Xia L, Yang S, Uszynski G, Mohler V, Lehmensiek A, Kuchel H, Hayden MJ, Howes N, Sharp P, Vaughan P, Rathmell B, Huttner E, Kilian A (2006) Diversity arrays technology (DArT) for high-throughput profiling of the hexaploid wheat genome. Theor Appl Genet 113:140920

Alexander J, Benford D, Boobis A, Ceccatelli S, Cottrill B, Cravedi J, Di Domenico A, Doerge D, Dogliotti E, Edler L, Farmer P, Filipič M, Fink-Gremmels J, Fürst P, Guérin T, Knutsen HK, Machala M, Mutti A, Rose M, Schlatter J, van Leeuwen R (2012) EFSA Panel on Contaminants in the Food Chain (CONTAM): Scientific Opinion on Ergot alkaloids in food and feed. EFSA Journal 10: 2798. 1-158 pp. doi:10.2903/j.efsa.2012.2798. www.efsa.europa.eu/efsajournal

Appleford NE, Lenton JR (1991) Gibberellins and leaf expansion in near-isogenic wheat lines containing Rht1 and Rht3 dwarfing alleles. Planta183:229-236

Bayles R, Fletcher M, Gladders P, Hall R, Hollins W, Kenyon D, Thomas J, West J (2008) Towards a sustainable whole-farm approach to the control of Ergot. HGCA Project No. 2992. LINK Project code LK0963

Broman KW, Wu H, Sen Ś, Churchill GA (2003) R/qtl: QTL mapping in experimental crosses. Bioinformatics 19:889-890

Broman KW, Sen Ś (2009) A Guide to QTL Mapping with R/qtl. Statistics for Biology and Health, DOI 10.1007/978-0-387-92125-9 3, Springer Science + Business Media, LLC 2009

Cheng H, Qin L, Lee S, Fu X, Richards DE, Cao D, Luo D, Harberd NP, Peng J (2004) Gibberellin regulates Arabidopsis floral development via suppression of DELLA protein function. Development 131:1055-64

Cooke RC, Mitchell DT (1966) Sclerotium size and germination in Claviceps purpurea. Transactions of the British Mycological Society 49:95-100 
De Costa C (2002) St Anthony's Fire and living ligatures: a short history of ergometrine. The Lancet 359:176870

De Groot AN, van Dongen PW, van Roosmalen J, Eskes TK (1993) Ergotamine-induced fetal stress: review of side effects of ergot alkaloids during pregnancy. European Journal of Obstetrics, Gynecology and Reproductive Biology 51:73-77

Diethelm M, Schmolke M, Groth J, Friedt W, Schweizer G, Hartl L (2014) Association of allelic variation in two NPR1-like genes with Fusarium head blight resistance in wheat. Molecular Breeding 34:31-43

Dill A, Thomas SG, Hu J, Steber CM, Suna T (2004) The Arabidopsis F-Box Protein SLEEPY1 Targets Gibberellin Signaling Repressors for Gibberellin-Induced Degradation. The Plant Cell 16:1392-1405

Draeger R, Gosman N, Steed A, Chandler E, Thomsett M, Srinivasachary, Shondelmaier J, Buerstmayr H, Lemmens M, Schmolke M, Mesterhazy A, Nicholson P (2007) Identification of QTLs for resistance to Fusarium head blight, DON accumulation and associated traits in the winter wheat variety Arina. Theor Appl Genet 115:617-625

Fulton TM, Chunwongse J, Tanksley SD (1995) Microprep protocol for extraction of DNA from tomato and other herbaceous plants. Plant Molecular Biology Reporter 13:207-209

Genstat 12 Committee (2009) Genstat for Windows release 12.0 VSN International, Wilkinson House

Hilton AJ, Jenkinson TW, Hollins TW, Parry DW (1999) Relationship between cultivar height and severity of Fusarium ear blight in wheat. Plant Pathol 48:1365-3059

Holland JB, Nyquist WE, Cervantes-Martinez CT (2010) Estimating and Interpreting Heritability for Plant Breeding: An Update. Plant Breeding Reviews 22 Chapter 2, 9-112 
Huang BE, George AW, Forrest KL, Kilian A, Hayden MJ, Morell MK, Cavanagh CR (2012) A multiparent advanced generation inter-cross population for genetic analysis in wheat. Plant Biotechnology Journal 10: 826839

Lin F, Xue SL, Zhang ZZ, Zhang CQ, Kong ZX, Yao GQ, Tian DG, Zhu HL, Li CJ, Cao Y, Wei JB, Luo QY, Ma ZQ (2006) Mapping QTL associated with resistance to Fusarium head blight in the Nanda2419 x Wangshuibai population. II: Type I Resistance. Theor Appl Genet 112:528-535

Lorieux M (2012) MapDisto: fast and efficient computation of genetic linkage maps. Molecular Breeding 30:1231-1235

Mantle PG, Shaw S (1976) Role of ascospore production by Claviceps purpurea in aetiology of ergot disease in male sterile wheat. Transactions of the British Mycological Society 67:17-22

Menzies JG (2004) The reactions of Canadian spring wheat genotypes to inoculation with Claviceps purpurea, the causal agent of ergot. Canadian Journal of Plant Sci 84:625-629

Navarro L, Bari R, Achard P, Lison P, Nemri A, Harberd NP, Jones JDG (2008) DELLAs control plant immune responses by modulating the balance and salicylic acid signalling. Current Biology 18, 650-655

Pageau D, Lajeunesse J (2006) Evaluation of the resistance of barley and wheat to ergot caused by Claviceps purpurea. Phytoprotection 87:63-68

Parh DK, Jordan DR, Aitken EA, Mace ES, Jun-ai P, McIntyre CL, Godwin ID (2008) QTL analysis of ergot resistance in sorghum. Theor Appl Genet 117:369-82

Payne RW, Murray DA, Harding SA, Baird DB, Soutar DM (2009). GenStat for Windows (12th Edition) Introduction. VSN International, Hemel Hempstead 
Pearce S, Saville R, Vaughan SP, Chandler PM, Wilhelm EP, Sparks CA, Al-Kaff N, Korolev A, Boulton MI, Phillips AL, Hedden P, Nicholson P, Thomas SG (2011). Molecular characterization of Rht-1 dwarfing genes in hexaploid wheat. Plant Physiol 157:1820-1831

Peng JR and Harberd NP (1997) Gibberellin deficiency and response mutations suppress the stem elongation phenotype of phytochrome-deficient mutants of Arabidopsis. Plant Physiol 113:1051-1058

Peng JR, Richards DE, Hartley NM, Murphy GP, Devos KM, Flintham JE, Beales J, Fish LJ, Worland AJ, Pelica F et al. (1999) 'Green Revolution' genes encode mutant gibberellin response modulators. Nature 40:256261

Platford RG, Bernier CC (1970) Resistance to Claviceps purpurea in Spring and Durum Wheat. Nature 226:770

Saville RJ, Gosman N, Burt CJ, Makepeace J, Steed A, Corbitt M, Chandler E, Brown JKM, Boulton MI, Nicholson P (2012) The 'Green Revolution’ dwarfing genes play a role in disease resistance in Triticum aestivum and Hordeum vulgare. Journal of Exp Botany 63:1271-1283

Spoel SH, Koornneef A, Claessens SM, Korzelius JP, Van Pelt JA, Mueller MJ, Buchala AJ, Métraux JP, Brown R, Kazan K, Van Loon LC, Dong X, Pieterse CM (2003) NPR1 modulates cross-talk between salicylateand jasmonate-dependent defense pathways through a novel function in the cytosol. Plant Cell 15:760-70

Srinivasachary, Gosman N, Steed A, Hollins TW, Bayles R, Jennings P, Nicholson P (2009) Semi-dwarfing Rht-B1 and Rht-D1 loci of wheat differ significantly in their influence on resistance to Fusarium head blight Theor Appl Genet 118 695-702

Tenberge K (1999) Ergot - The Genus Claviceps. In: Kven and Cvak (ed) Biology and life strategy of the ergot fungi. Harwood Academic publishers, pp25-56

Tudzynski B, Hölter K (1998) Gibberellin biosynthetic pathway in Gibberella fujikuroi: evidence for a gene cluster. Fungal Genet Biol 25:157-170 
Tudzynski B (2005) Gibberellin biosynthesis in fungi genes enzymes evolution. Applied Microbiology and Biotechnology J

Tudzynski P, Schieffer J (2004) Claviceps purpurea: molecular aspects of a unique pathogenic lifestyle. Molecular Plant Pathol 5:1364-3703

Wang S, Wong D, Forrest K, Allen A, Chao S, Huang BE, Maccaferri M, Salvi S, Milner SG, Cattivelli L, Mastrangelo AM, Whan A, Stephen S, Barker G, Wieseke R, Plieske J, International Wheat Genome Sequencing Consortium, Lillemo M, Mather D, Appels R, Dolferus R, Brown-Guedira G, Korol A, Akhunova AR, Feuillet C, Salse J, Morgante M, Pozniak C, Luo MC, Dvorak J, Morell M, Dubcovsky J, Ganal M, Tuberosa R, Lawley C, Mikoulitch I, Cavanagh C, Edwards KJ, Hayden M, Akhunov E (2014) Characterization of polyploid wheat genomic diversity using a high-density 90000 single nucleotide polymorphism array. Plant Biotechnol J 12: 787-796

Watanabe N (2008) Genetic collection and development of near-isogenic lines in durum wheat. Вестник ВОГиС (Journal VOGiS), 12: 636-643

Wilhelm E (2011) Genetic analysis of the Group IV Rht Loci in wheat. Doctoral thesis, University of East Anglia

Wilkinson PA, Winfield MO, Barker GL, Allen AM, Burridge A, Coghill JA, Edwards KJ (2012) CerealsDB 2.0: an integrated resource for plant breeders and scientists. BMC Bioinformatics 3:219

Wu J, Kong X, Wan J, Liu X, Zhang X, Guo X, Zhou R, Zhao G, Jing R, Fu X, Jia J (2011) Dominant and Pleiotropic Effects of a GAI Gene in Wheat Results from a Lack of Interaction between DELLA and GID1. Plant Physiology, 157:2120-2130 
Figure 2

Click here to download Figure: Fig 2.pptx

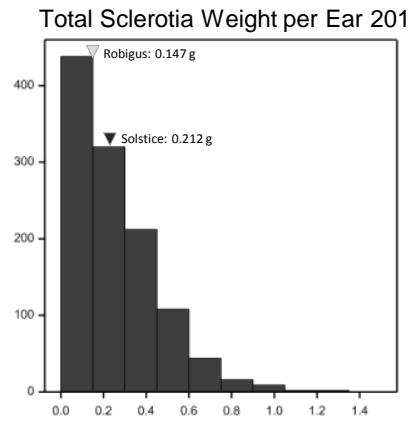

Total Sclerotia Weight per Ear 2011 / g
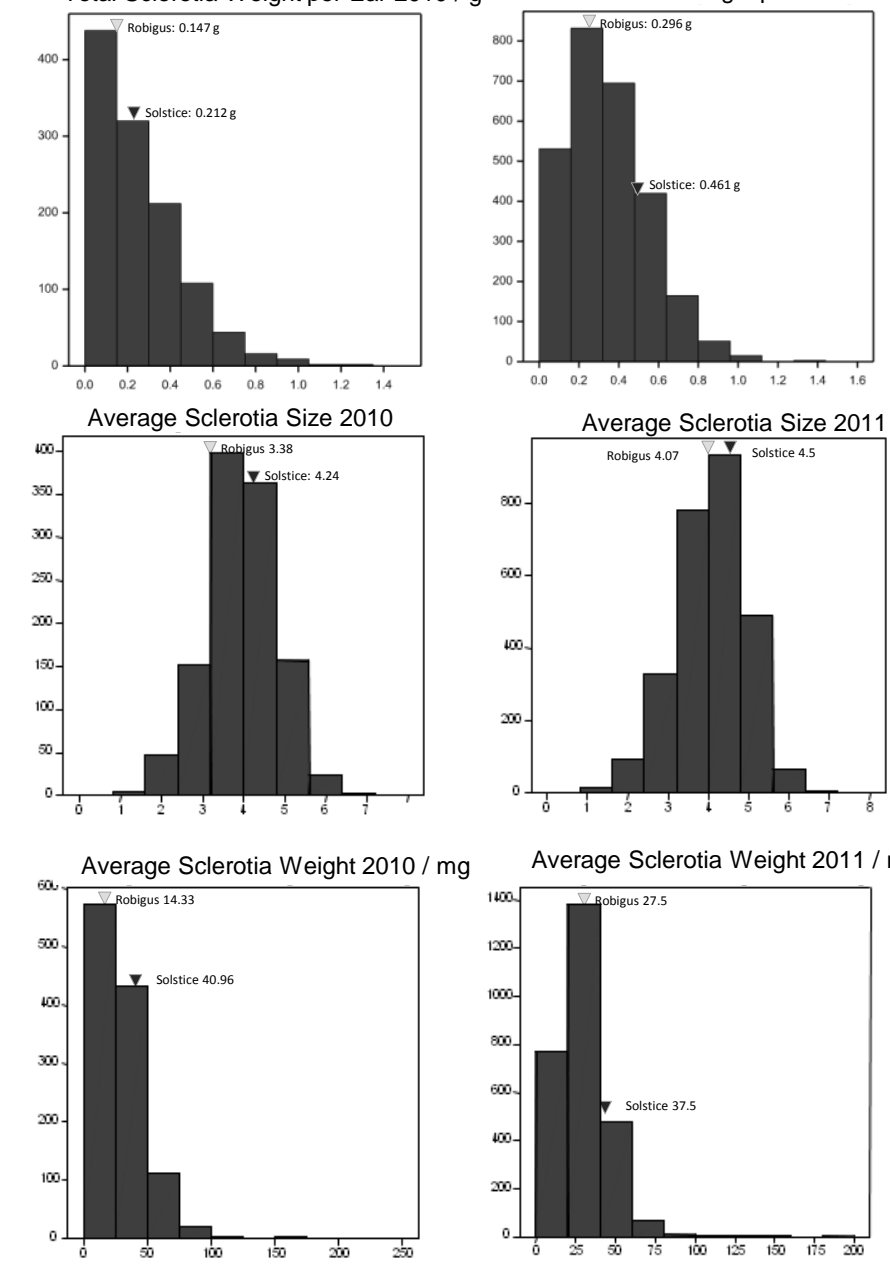

Average Sclerotia Weight 2011 / mg
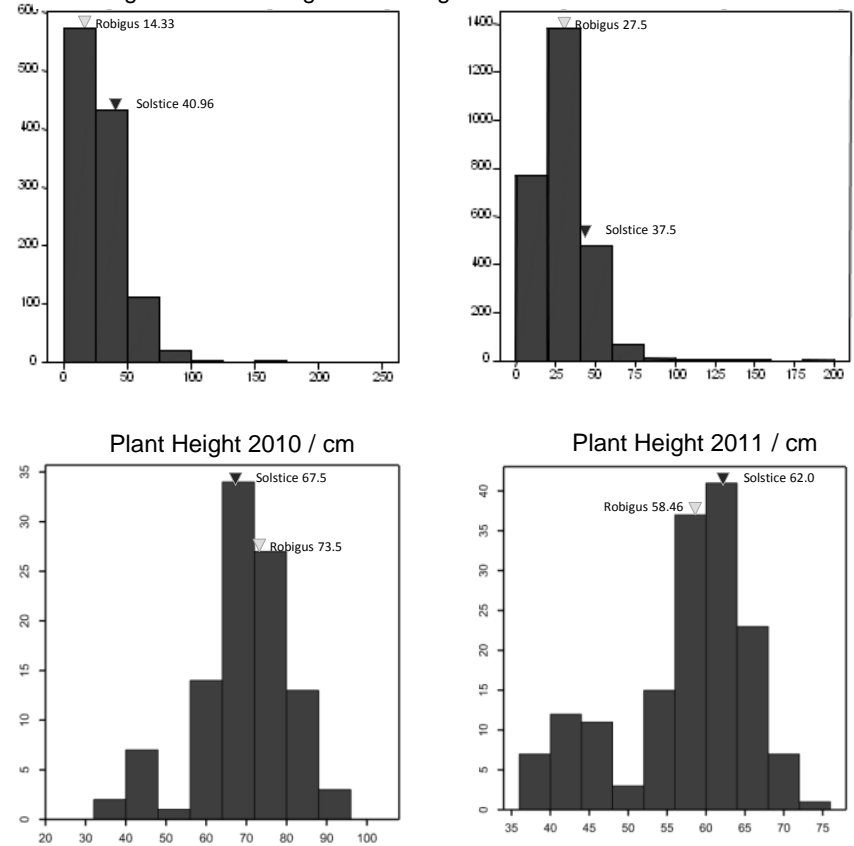
Figure 3

Click here to download Figure: Fig 3.pptx

2A

$6 A$

4B

4D
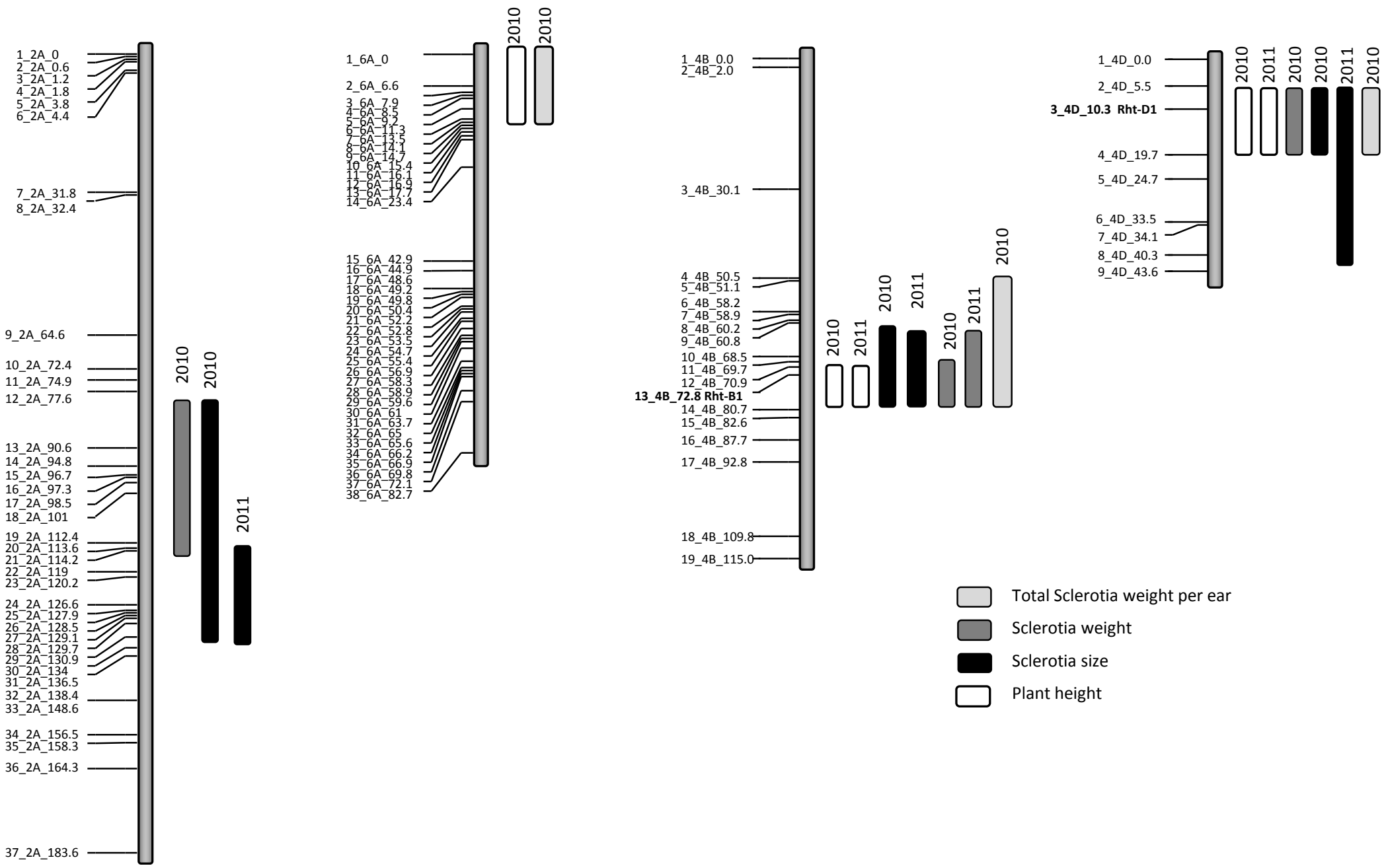

13 . $124 \mathrm{~B}^{-69.7} 70.9$

_72.8 Rht-B1

${ }_{15}^{14}-4 \mathrm{~B}-80.7$

16_4B_87.7

17_4B_92.8 -

荢 莒

궁

$6-4 B-58.2$

7- $48-58.9$

$8-48-60.2 \equiv$

웜 न्ष

it odilíl

19 4B 115

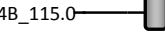

$\square$ Total Sclerotia weight per ear

$\square$ Sclerotia weight

Sclerotia size

$\square$ Plant height 
Click here to download Figure: Fig 4 A pptx

2A Origin: Robigus Peak marker: wsnp_BQ168780B_Ta_2_1

$4 \mathrm{~B}$ Origin: Robigus

Peak marker: Rht-B1

4D Origin: Solstice

Peak marker: Rht-D1

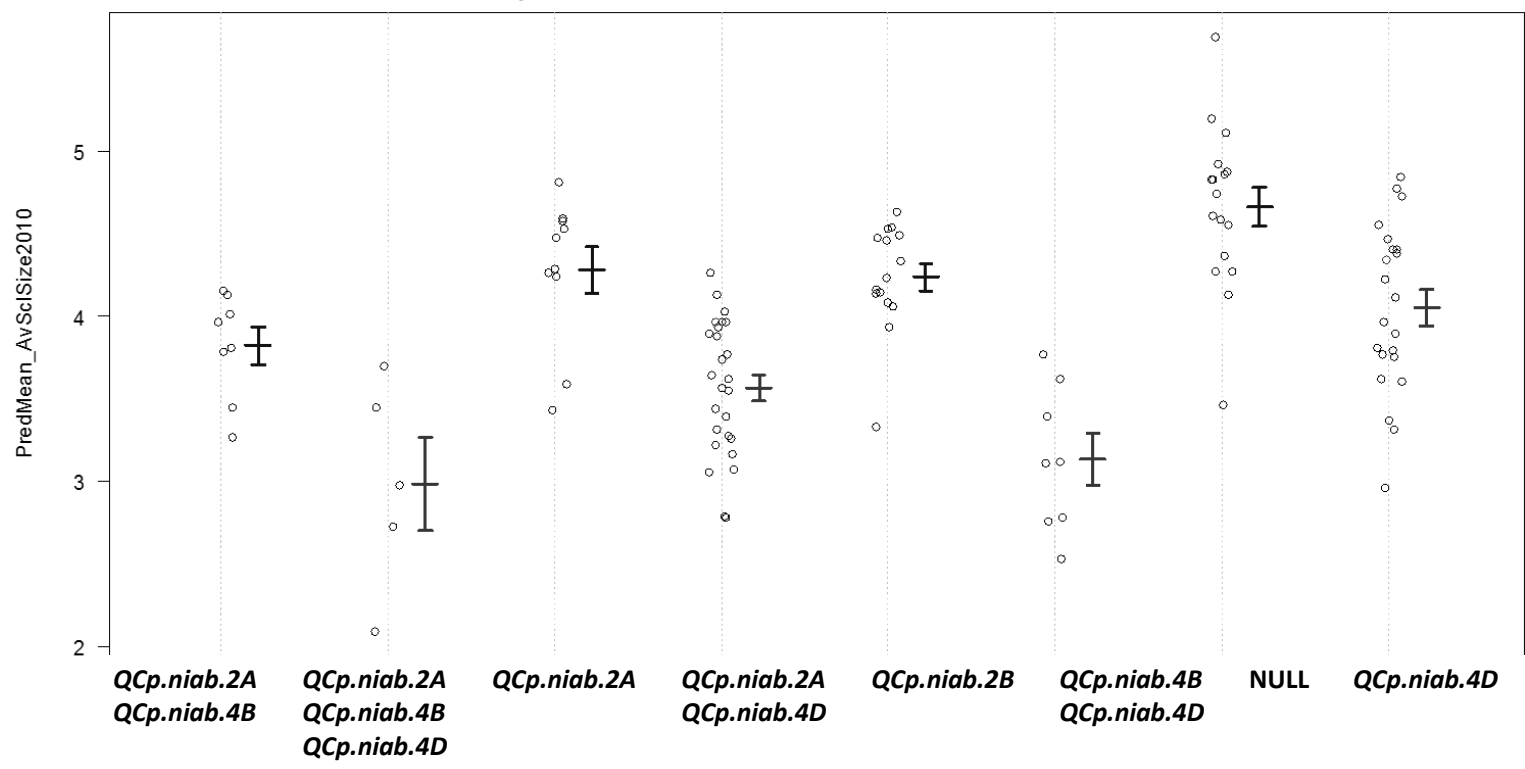

2A Origin: Robigus Peak marker: wsnp_Ex_c2337_4379619

4B Origin: Robigus Peak marker: wsnp_CAP12_c138078

4D Origin: Solstice Peak marker: Rht-D1

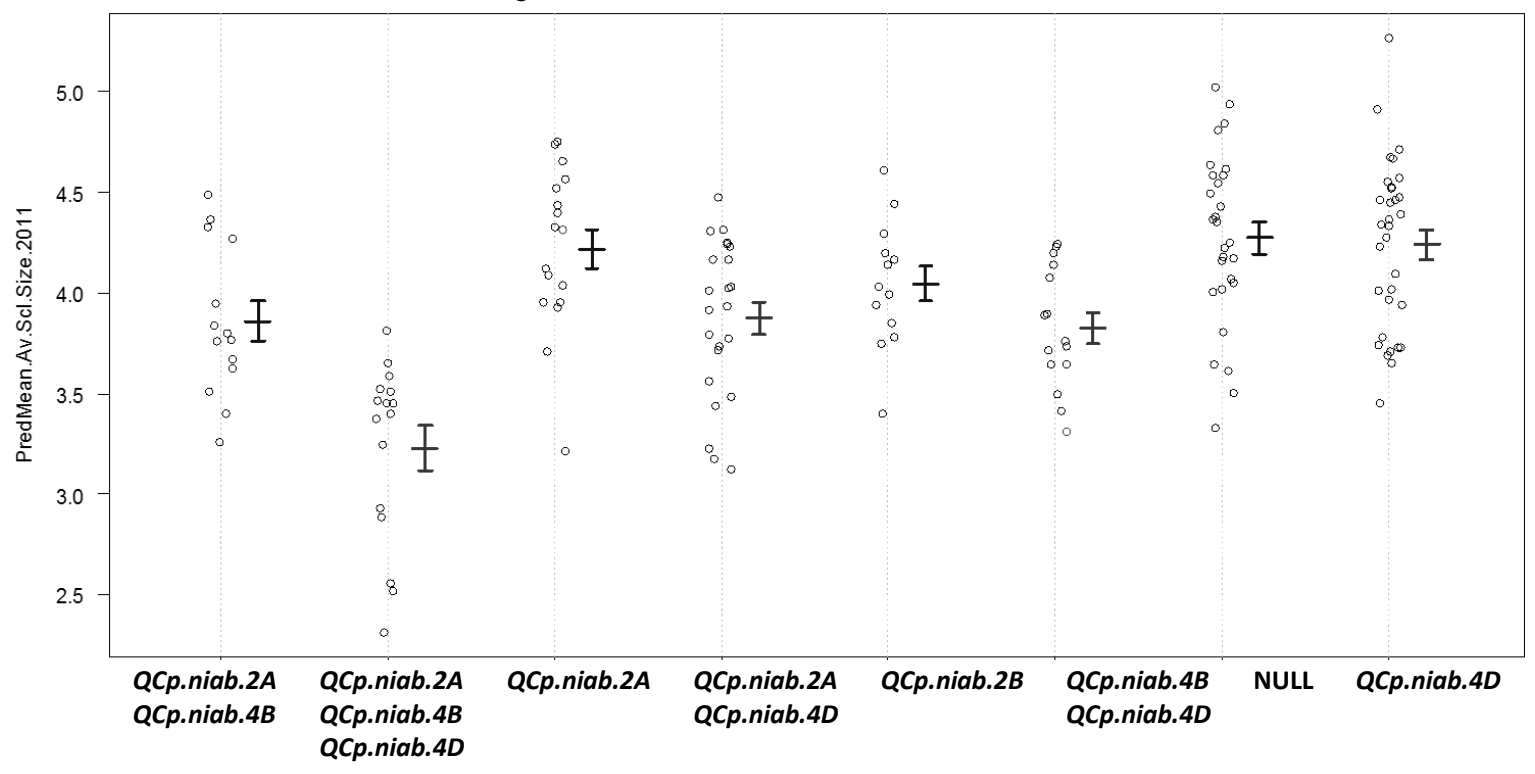


Click here to download Figure: Fig 5.pptx

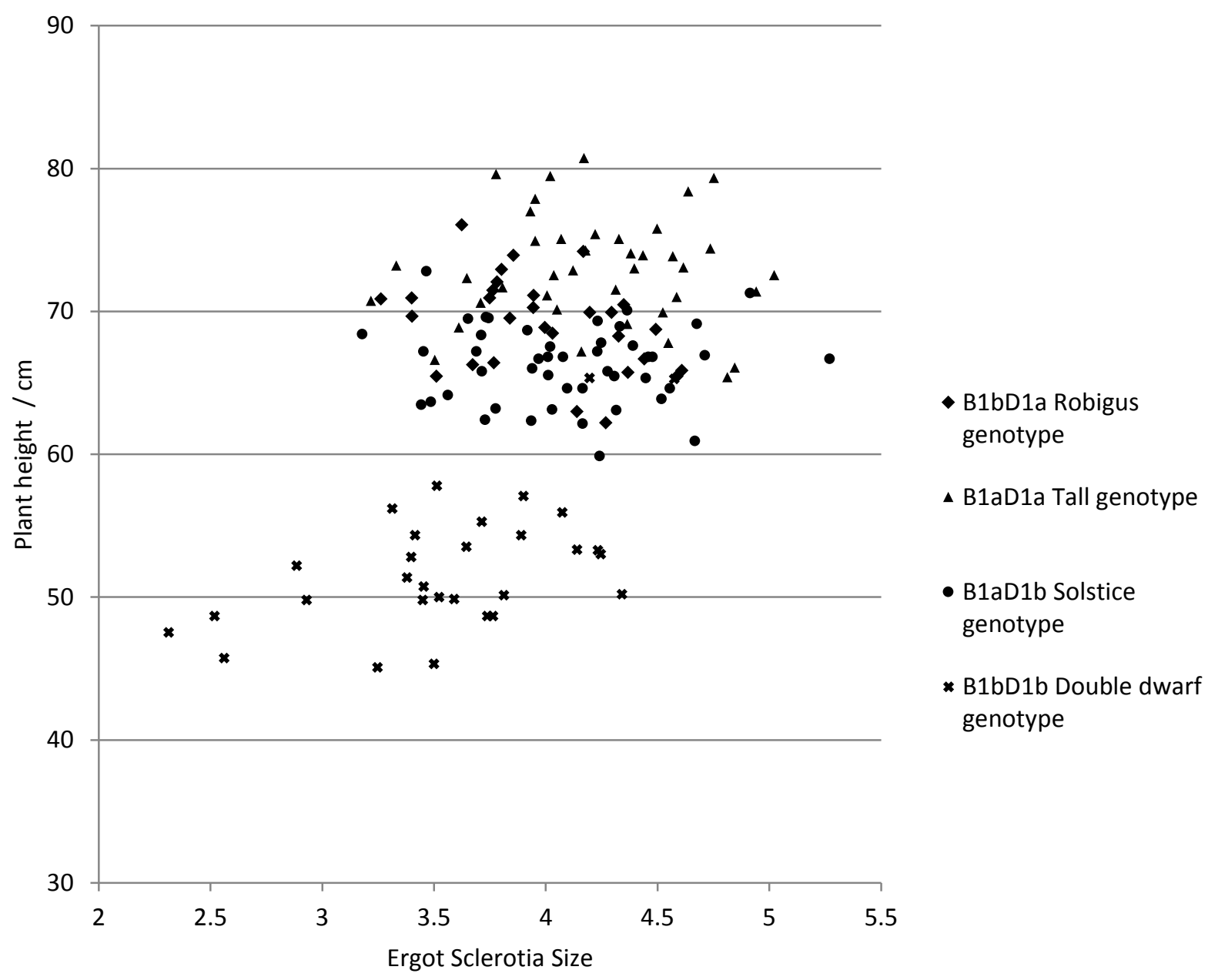


Click here to download Supplementary Material (builds into PDF): ESM_1.pptx

\section{Sclerotia Sizing Scale for Claviceps purpurea}

\begin{tabular}{|c|c|c|c|c|c|c|c|c|}
\hline Scale & 0 & 1 & 2 & 3 & 4 & 5 & 6 & 7 \\
\hline $\begin{array}{l}\text { Example } \\
\text { sclerotia }\end{array}$ & 8 & ? & 8 & $\begin{array}{l}0 \\
8 \\
8\end{array}$ & 8 & & & \\
\hline $\begin{array}{c}\text { Length } \\
\text { range / } \\
\mathrm{mm}\end{array}$ & 0 & $\geq 1.5$ & $1.5-3$ & $3-4.5$ & $4.5-7$ & 7-9 & $9-11$ & $\geq 11$ \\
\hline $\begin{array}{c}\text { Width } \\
\text { range / } \\
\text { mm }\end{array}$ & 0 & $\geq 1.5$ & $1.5-2$ & $\geq 2.5$ & $\geq 2.5$ & $\geq 3$ & $\geq 4$ & $>4$ \\
\hline $\begin{array}{l}\text { Further } \\
\text { comments }\end{array}$ & $\begin{array}{l}\text { Infection but } \\
\text { no sclerotia } \\
\text { formed. } \\
\text { No seed set }\end{array}$ & $\begin{array}{l}\text { Sclerotia that } \\
\text { are the size } \\
\text { of an ovary- } \\
\text { usually round }\end{array}$ & $\begin{array}{c}\text { Sclerotia that } \\
\text { are larger } \\
\text { than the size } \\
\text { of an ovary- } \\
\text { usually } \\
\text { oblong }\end{array}$ & $\begin{array}{l}\text { Sclerotia that } \\
\text { are smaller } \\
\text { than a seed }\end{array}$ & $\begin{array}{l}\text { Sclerotia that } \\
\text { are approx } \\
\text { the size of a } \\
\text { wheat seed }\end{array}$ & $\begin{array}{l}\text { Sclerotia that } \\
\text { completely } \\
\text { fill the seed } \\
\text { cavity }\end{array}$ & $\begin{array}{c}\text { Sclerotia } \\
\text { visible before } \\
\text { extracting } \\
\text { from ear }\end{array}$ & $\begin{array}{l}\text { Massive. } \\
\text { More than } \\
\text { half is } \\
\text { extending } \\
\text { from the } \\
\text { glumes }\end{array}$ \\
\hline
\end{tabular}




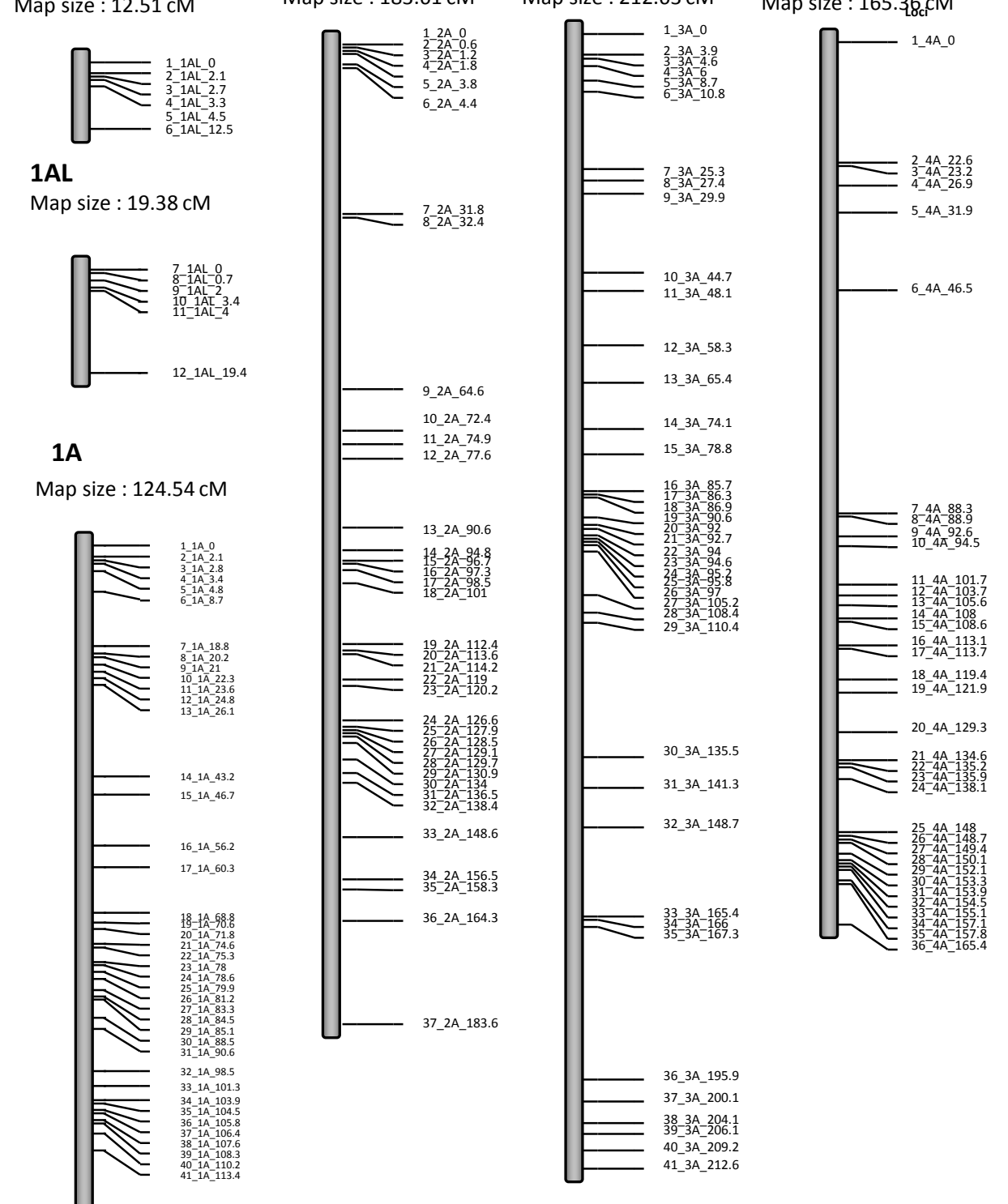

ap size $: 251.75 \mathrm{cM}$ Map size : $82.69 \mathrm{cM}$
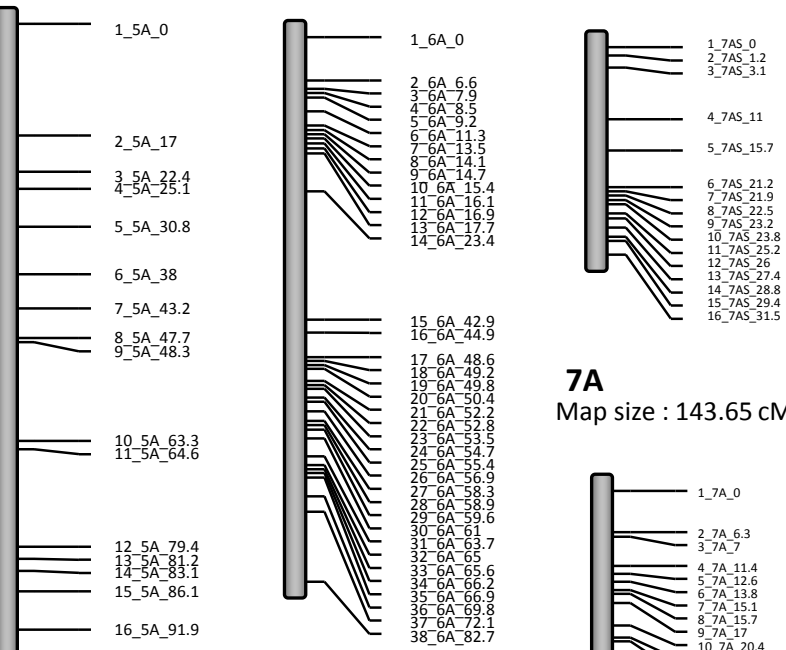

$7 A$

Map size : $143.65 \mathrm{cM}$

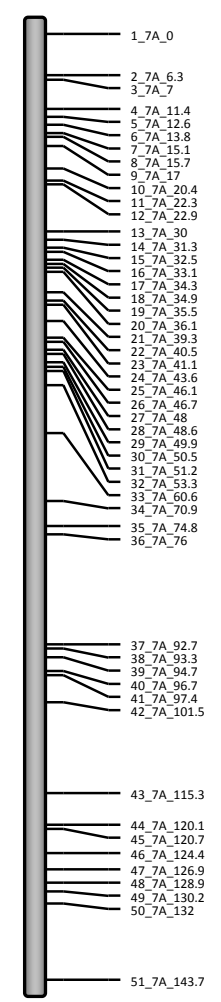

42_-1A.1245

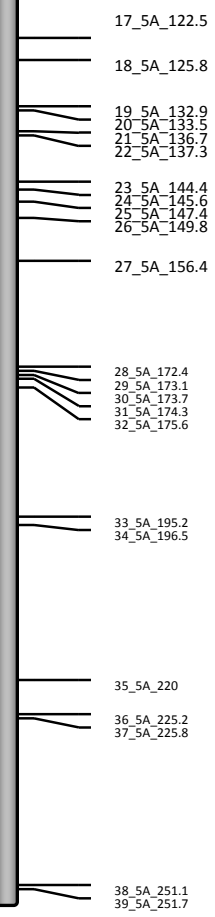



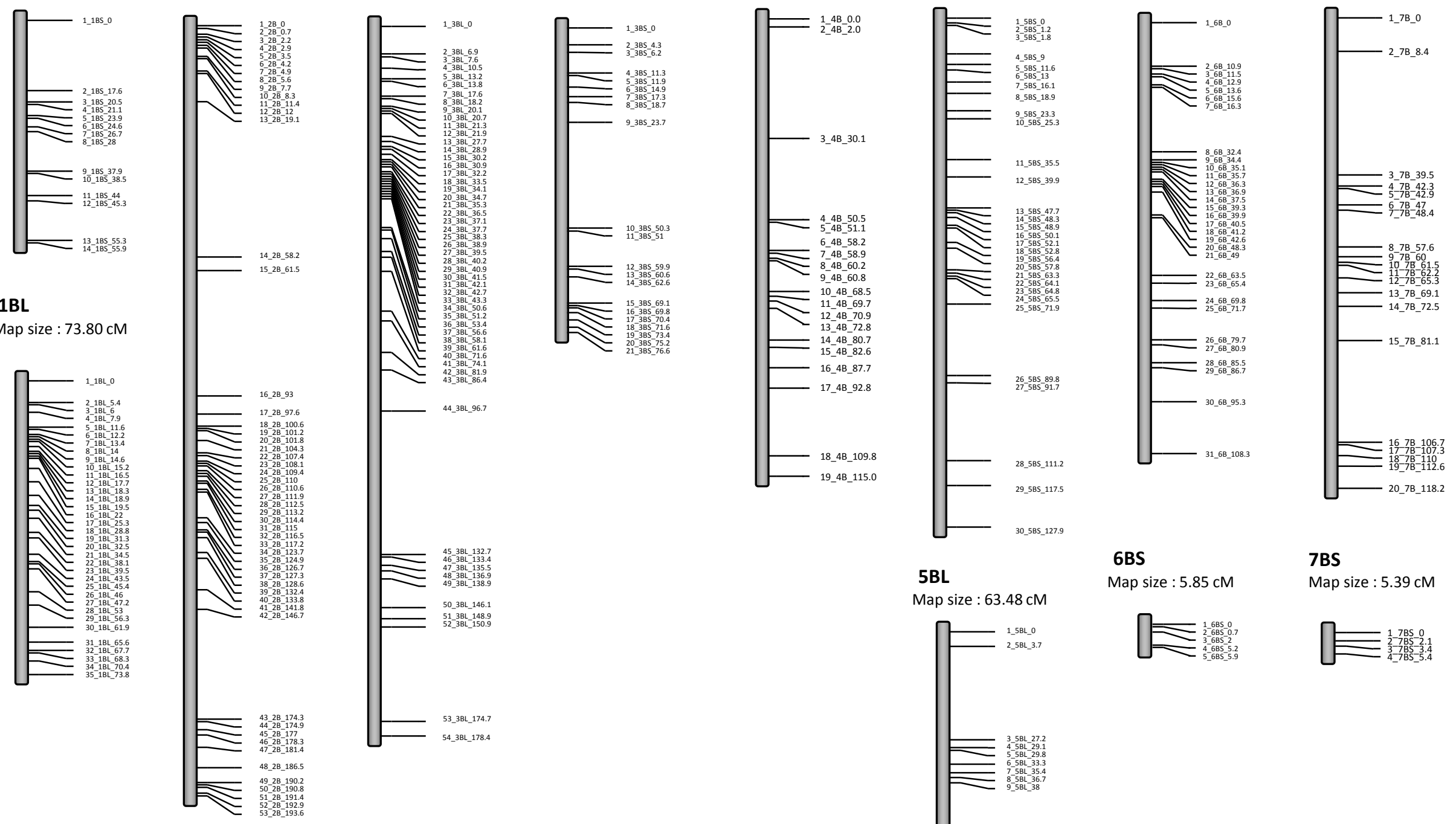

5BL

Map size : $63.48 \mathrm{cM}$

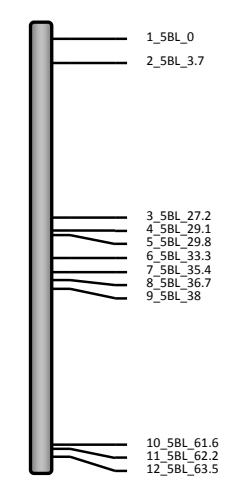

6BS

Map size : $5.85 \mathrm{cM}$

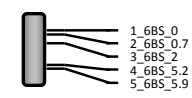

7BS

Map size : $5.39 \mathrm{cM}$

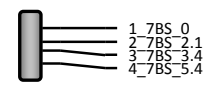


1D 2D

Map size : 118.34 cM Map size : 80.89 A cM

3D

Map size : $49.31 \mathrm{cM}$

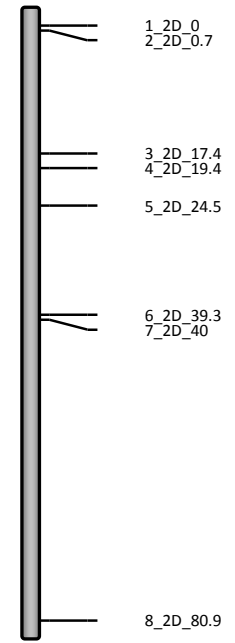

2DL

Map size : $11.92 \mathrm{cM}$

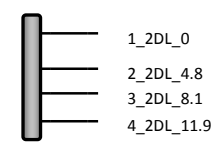

4D

Map size : $43.6 \mathrm{cM}$

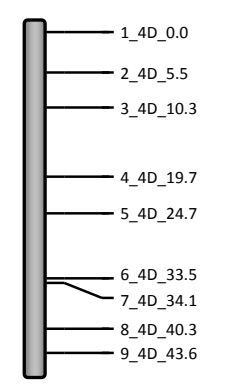

$14 \_3 D-49.3$
5D

Map size : $62.12 \mathrm{cM}$

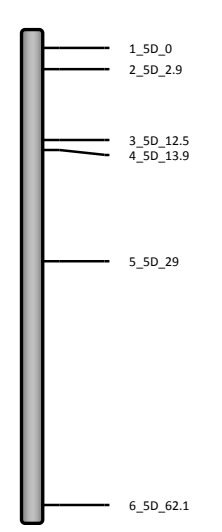

5DL

Map size : $28.00 \mathrm{cM}$

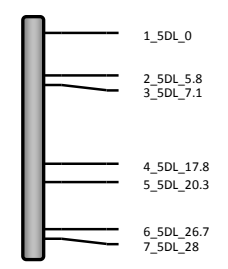

6D

Map size : $10.56 \mathrm{cM}$

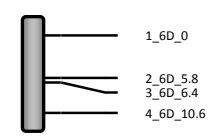

7D

Map size : $43.90 \mathrm{cM}$

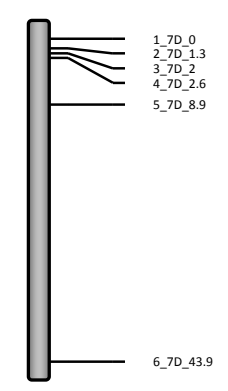

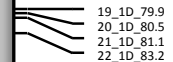

$-23 \_10 \_109.6$ 
A QCp.niab.6A

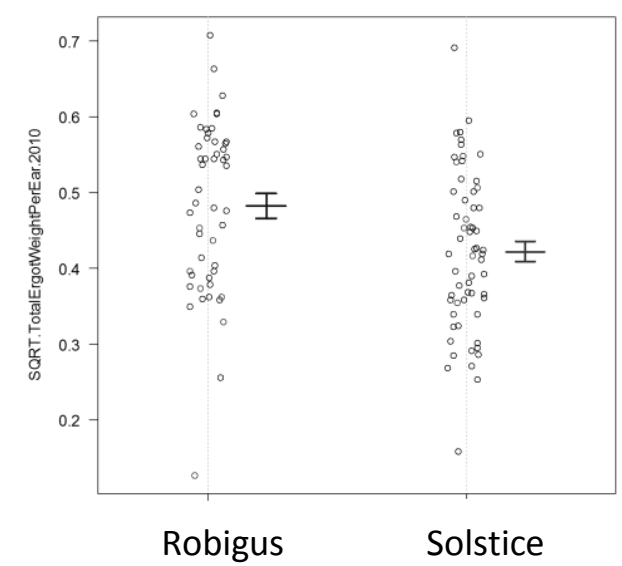

B

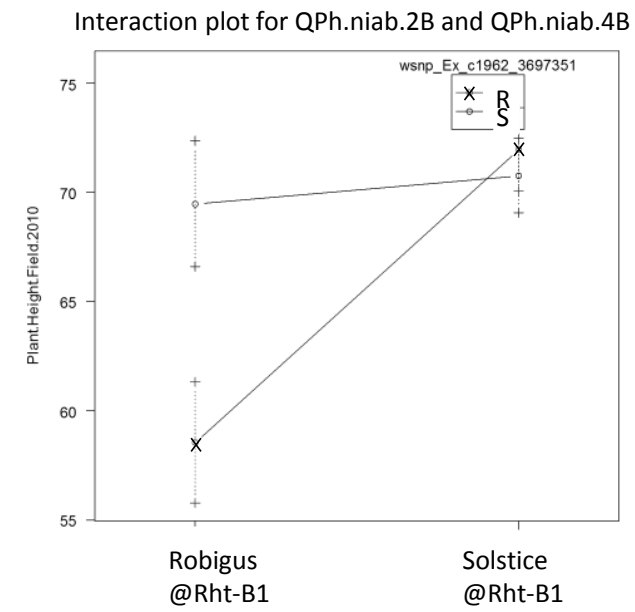

QPh.niab.6A

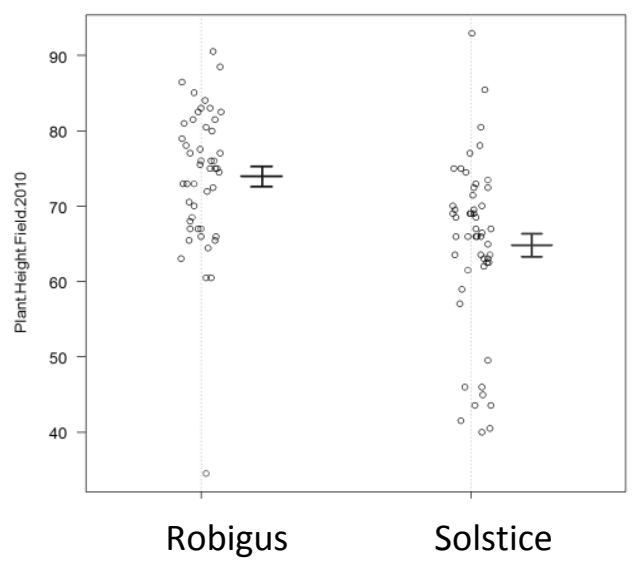

Dot plot for QPh.niab.2B and QPh.niab.4B

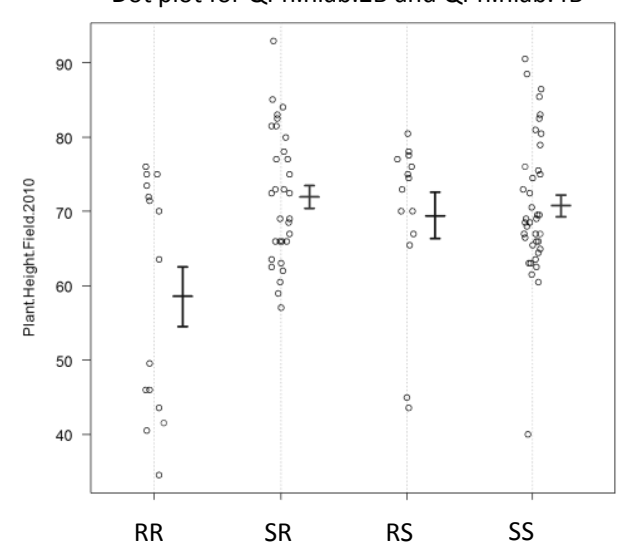




\begin{tabular}{|c|c|c|c|c|c|c|c|c|c|c|c|c|c|c|}
\hline QTL & Phenotype & $\begin{array}{c}\text { Chromosomal } \\
\text { locations }\end{array}$ & $\begin{array}{l}\text { Position } \\
\text { QTL1 full }\end{array}$ & $\begin{array}{l}\text { Position } \\
\text { QTL2 full }\end{array}$ & $\begin{array}{l}\operatorname{LOD}_{\mathrm{f}} \\
(\mathrm{V} \\
\text { null })\end{array}$ & $\operatorname{LOD}_{\mathrm{fv} 1}$ & $\begin{array}{c}P \\
\text { value } \\
\text { fv1 }\end{array}$ & $\operatorname{LOD}_{i}$ & $\begin{array}{c}P \\
\text { value }\end{array}$ & $\begin{array}{l}\text { Position } \\
\text { QTL1 add }\end{array}$ & $\begin{array}{l}\text { Position } \\
\text { QTL2 add }\end{array}$ & $\operatorname{LOD}_{\mathrm{av} 1}$ & $\begin{array}{c}\mathrm{P} \\
\text { value } \\
\text { av1 }\end{array}$ & $\begin{array}{c}\text { Relationship } \\
\text { between the } \\
\text { QTL pairs }\end{array}$ \\
\hline $\begin{array}{l}\text { QCp.niab.2A } \\
\text { QCp.niab.4B }\end{array}$ & \multirow{2}{*}{ Ergot size 2010} & $2 A: 4 B$ & 100 & 12.5 & 12.2 & 3.11 & 0.974 & 0.0724 & 1 & 100 & 12.5 & 3.03 & 0.072 & Additive \\
\hline $\begin{array}{l}\text { QCp.niab.4B } \\
\text { QCp.niab.4D }\end{array}$ & & $4 \mathrm{~B}: 4 \mathrm{D}$ & 75 & 12.5 & 16.2 & 7.06 & 0 & 0.2468 & 1 & 75 & 12.5 & 6.81 & 0 & Additive \\
\hline $\begin{array}{l}\text { QCp.niab.2A } \\
\text { QCp.niab.4B }\end{array}$ & \multirow{2}{*}{ Ergot size 2011} & $2 A: 4 B$ & 132 & 70 & 10.8 & 4.35 & 0.344 & 0.419 & 1 & 132 & 70 & 3.93 & 0.037 & Additive \\
\hline $\begin{array}{l}\text { QCp.niab.4B } \\
\text { QCp.niab.4D }\end{array}$ & & $4 \mathrm{~B}: 4 \mathrm{D}$ & 67.5 & 25 & 10.7 & 4.21 & 0.421 & 1.199 & 1 & 70 & 2.5 & 3.01 & 0.172 & Additive \\
\hline $\begin{array}{l}\text { QPh.niab.2B } \\
\text { QPh.niab.4B }\end{array}$ & \multirow{2}{*}{$\begin{array}{l}\text { plant height } \\
2010\end{array}$} & $2 \mathrm{~B}: 4 \mathrm{~B}$ & 40 & 75 & 19.16 & 8.15 & 0 & 7.37 & 0 & 110 & 72.5 & 0.78 & 1 & Interacting \\
\hline $\begin{array}{l}\text { QPh.niab.4B } \\
\text { QPh.niab.4D }\end{array}$ & & 4B:4D & 75 & 12.5 & 57.66 & 39.97 & 0 & 16.01 & 0 & 72.5 & 10 & 23.968 & 0 & $\begin{array}{c}\text { Both } \\
\text { interacting } \\
\text { and additive }\end{array}$ \\
\hline $\begin{array}{l}\text { QPh.niab.4B } \\
\text { QPh.niab.4D }\end{array}$ & $\begin{array}{l}\text { plant height } \\
2011\end{array}$ & 4B:4D & 75 & 10 & 32.1 & 19.63 & 0 & 7.84 & 0 & 72.5 & 10 & 11.79 & 0 & $\begin{array}{c}\text { Both } \\
\text { interacting } \\
\text { and additive }\end{array}$ \\
\hline
\end{tabular}


Online Resource 2

Click here to download Supplementary Material (download option from within PDF): ESM_2.xlsx 